九州大学学術情報リポジトリ

Kyushu University Institutional Repository

\title{
A Revision of the Family Pselaphidae (Coleoptera) from South Korea
}

Nomura, Shuhe i

Lee, Chang Eon

https://doi.org/10.5109/2561

出版情報 : ESAKIA. 33，pp.1-48，1993-03-31. Entomological Laboratory，Faculty of Agriculture， Kyushu University

バージョン :

権利関係 : 
ESAKIA, (33): 1-48. March 31, 1993

\title{
A Revision of the Family Pselaphidae (Coleoptera) from South Korea ${ }^{1,2,}$
}

\author{
Shûhei NOMURA \\ Entomological Laboratory, Faculty of Agriculture, Kyushu \\ University, Fukuoka, 812 Japan \\ and \\ Chang Eon LeE \\ Department of Biology, College of Natural Sciences, Kyungpook \\ National University, Taegu, 702-701 Korea
}

\begin{abstract}
This is the second revision of the family Pselaphidae from South Korea treating twenty-nine species, of which fifteen species arc new to science and six species are new to the fauna of South Korea. New species are Philoscotus coreanus, Batrisodes baejeongdoki, Basitrodes myrmecophilus, Batriscenellus brachygaster, Nipponobythus longicollis, Trissemus peninsulanus, Bryaxis nogodanensis, $B$. macheonensis, $B$. kimjongkuki, $B$. leechanyoungi, $B$. chilimontanus, $B$. peninsulanus, Tainochus abdominalis, Dicentrius cornurus, Curculionellus komyungkyuneae. Species new to the fauna of South Korea are Batrisus sibiricus Sharp, Rybaxis lamellifer Löbl, Batraxis splendida Nomura, Pilopius mroczkowskii (Löbl), Sognorus breviceps (Sharp), Paracyathiger fujiyamai (Kubota).
\end{abstract}

\section{INTRODUCTION}

The family Pselaphidae had been little known from South Korea until Nomura \& Lee (1992) recorded ten species from Chejudo island. Present paper deals with twenty-nine species collected

1) Results from the Korea-Japan Co-operative Science Program on "The Evolution and Biogeography of the Insects in the East Asia". No. 11.

2) Contribution from the Entomological Laboratory, Faculty of Agriculture, Kyushu University, Fukuoka (Ser. 4, No. 45). 
from southern part of Korean Peninsula and Namhaedo Is. (Kyongsang-nam Do), in which fifteen species are new to science, six are firstly recorded from South Korea and four are undetermined.

\section{Subfamily EUPLECTINAE LeConte}

Tribe Euplectini s. str.

Subtribe Acetaliina Jeanne1

\section{Genus Philoscotus K. Sawada}

Philoscotus K. Sawada, 1957, Akitu, Kyoto, 6: 23; Besuchet, 1985, Rev. suisse Zool., 92: 766 (Philoscotus=Typhlacetalius); Nomura, 1988, Kontyû, Tokyo, 56(3): 515; Newton \& Chandler, 1989, Field. Zool., N. S., (53): 19. Type species: Philoscotus longulus K. Sawada, by original designation.

Typhlacetalius Jeannel, 1959a, Rev. fr. Ent., 26: 17. Type species: Typhlacetalius coiffaiti Jeannel, by monotypy.

The genus Philoscotus Sawada is closely allied to the genus Acetalius Sharp, but is easily distinguished by having a pair of well-demarcated paratergites on the fourth abdominal segment. This genus consists of nine Japanese species, which are classified into three species groups, namely the venustus-, brevis-, and long\&us-groups by their punctation on the dorsal surface of the body and the feature of the sculpture on the fore femora.

\section{Philoscotus coreanus sp. nov.}

Male. Unknown.

(Figs. 1A, D-K, 3A)

Female. Length 1.8-1.9 mm. Width $0.7 \mathrm{~mm}$.

Body reddish brown to light brown, strongly narrowed in head and pronotum.

Head elongately trapezoid, 1.3 times as long as wide, sparsely punctate, clypeus almost horizontal, limbate on its margin, frons weakly depressed between bases of antennae, vertex slightly convex, with a pair of clear dorsal tentorial pits, tempora weakly expanded. Eyes obsolete. Antennae short, reaching anterior part of pronotum, 1st to 2 nd segment subequal in length, each subcylindrical, 3rd to 8 th each ovoid, 9th to 10th each very short and transverse, 11th predominantly large, with a circle of bold setae at apical 1/3, subcylindrical at basal part, subconical and covered with bold setae and pubescence at apical part, relative length (width) of each segment from base to apex $1.0(0.7): 1.0$ (0.7): 0.5 (0.6): 0.4 (0.6): 0.4 (0.6): 0.4 (0.6): 0.4 (0.6): 0.4 (0.6): 0.5 (0.8): 0.5 (1.0): $2.6(2.0)$.

Pronotum ovoid in dorsal view, widest at anterior $2 / 5$, weakly convex and coarsely punctate, with 4 large depressions at about posterior 1/3. Elytra wider than long, widest at about posterior $1 / 3$, then narrowed anteriorly, weakly convex, each elytron with 4 basal foveae and 4 shallow longitudinal sulci (see remarks). Legs short, fore femora swollen at the middle, each with ovoid sculpture 

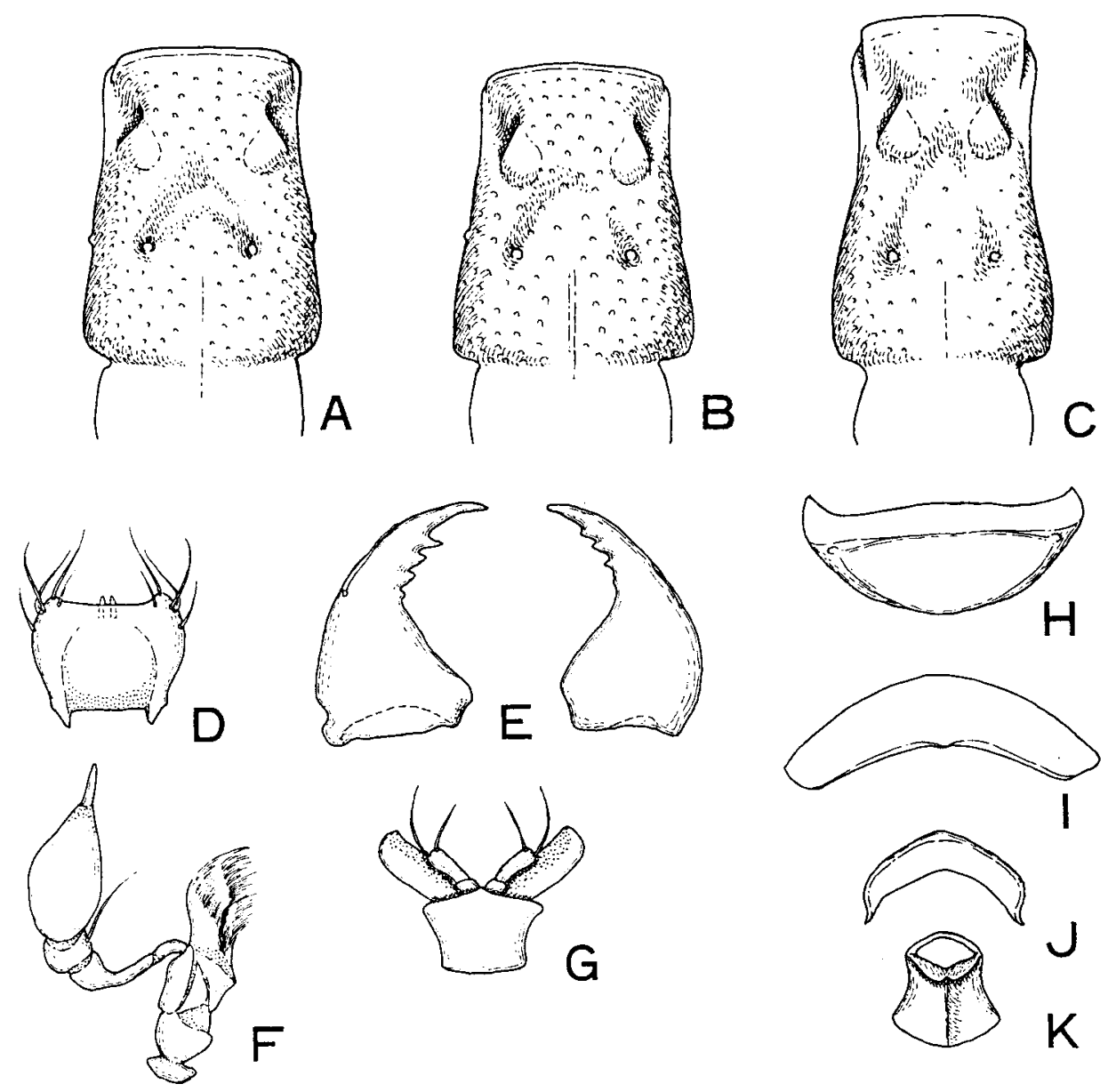

Fig. 1. A, D-K: Philoscotus coreanus sp. nov., female; B: P.longulus K. Sawada, female; C: I-1 rostralis Nomura, female. A-C: head in dorsal view; D, labrum; E, mandibles; F: maxilla; G: labium; H: 8th tergite; I: 8th sternite; J: 9th sternite; K: genital plate.

which is oblique in situation, about 2/5 times as long as the femur and strongly rugose on its bottom.

Abdomen slightly narrower than elytra, clearly transverse and rounded posteriorly, 4th segment largest, about twice as wide as long, with a shallow basidorsal depression between basidorsal carinae and a pair of basilateral foveae, the basidorsal depression 0.3 times as wide as the segment, 5th to 7th segments narrowed posteriorly, each very short, Sth tergite semicircular, rounded posteriorly, 6th sternite arcuate, weakly sclerotized on basal part, genital plate broadened basally, T-shaped in posterior view.

Distribution. South Korea (Mt. Chilisan). 
Holotype, female, Samjeoug Ri, Macheon Myeon, Namweon Gun, Cheonla-buk Do, 11. v. 1991, S. Nomura leg. Paratypes, 11 females, same data as holotype; 1 female, Jeouglyeon Chi, Samnae Myeon, Cheonla-buk Do, 12. vii. 1991, S. Nomura leg.

Remarks. This species belongs to the longulus-group by the coarse punctures on head and pronotum and a small, deep and ovoid sculpture of the fore femur. This species is very similar to $P$. longulus K. Sawada (Fig. 1B) and P.rostralis Nomura (Fig. 1C), but is separated from the former by the elongate and trapezoid head and an oblique sculpture of the fore femur, and from the latter by the shorter head and a broader dorsomedian depression on the fourth abdominal segment, which is 0.3 times as wide as the segment.

The terminal plate of the female abdomen in this group is considered to be the ninth tergite according to the revision of the subtribe Acetaliina from Japan (Nomura,1988a-c). Whereas the terminal plate is the ninth sternite and the vaginal opening is located between 8th and 9th sternites in my recent opinion.

\title{
Subfamily BATRISINAE Reitter
}

Tribe Batrisini s. str.

Subtribe Batrisina s. str.

\begin{abstract}
A Key to the Genera of the Subtribe Batrisina from South Korea (with Some Genera from its Adjacent Regions Put in Parentheses)
\end{abstract}

Elytra each with 3 basal foveae (division II sensu Jeannel)

Elytra each with 2 basal foveae (division V sensu Jeannel: Batrisocenus-complex by Nomura, 1991)

Body very robust, covered with short pubescence; maxillary palpi large and robust, 4th segment widest at apical part; pronotum round-sided and without longitudinal carinae . . . Batrisus Aubé Body slender; maxillary palpi small, 4th segment widest at basal part in general; pronotum with some longitudinal carinae 3

Pronotum with a pair of lateral denticles or projections near the middle, hind trochanters each with a posterior spine in male .

[Tribasodes etc. ${ }^{*}$ ]

Pronotum with a pair of round expansions on both sides

Eleventh antennal segment with a denticle at ventral side in male, mid tibiae each with a spine on posterior side in male [Batrisodellus etc.**]

Eleventh antennal segment without denticle in male

Head or antennae sexually dimorphic in many cases; male genitalia almost symmetrical with a large and quadrangular basal foramen Batrisodes Reitter

Head and antennae sexually monomorphic; male genitalia consisting of asymmetrical median lobe and endophallus Busitrodes Jeanne1 
6. Fourth abdominal segment with a pair of well-demarcated paratergites ..[Batrisoplisus Raffray]

- Paratergites of 4 th abdominal segment completely fused with tergite and sternite $\ldots \ldots \ldots \ldots \ldots \ldots .7$

7. First antenna1 segment without conical trichome, female genitalia composed of weakly sclerotized 9th sternite and T-shaped genital plate Batriscenellus Jeannel

- First antennal segment without conical trichome, female genitalia composed of 9th sternite with an ovoid membranous area and large genital plate with a pair of lateral arms

[Arthromelodes etc. $* * *$ ]

*: Tribasodes Jeannel, Tribasodites Jeannel, Batrisoschema Reitter and Coryphomodes Jeannel.

**: Batrisodellus Jeanne], Kigatrodes Jeannel and Speobatrisodes Jeannel.

***:Cratna Raffray, Batriscenaulax Jeannel, Physomerinus Jeannel, Arthromelodes Jeanne1 and Ba trisceniola Jeannel.

\section{Genus Batrisus Aubé}

Batrisus Aubé, 1833, Mag. Zool., 3: 4.5; Aubé, 1844, Ann. Soc. ent. Fr., 2(2): 80; Aubé, 1887, Er. Kaf. Mk. Brandbg., 1: 264; Aubé, 1857, Jaq. du Val, Gen. Col., Europ., 1: 130; Thomson, 1861, Skand. Col., 229; Saulcy, 1874, Bull. Soc. Hist. nat. Metz, 13: 90; Rcitter, 1881, Verh. Kais.-Königl.zool.-bot. Ges. Wien, 31: 451; Raffray, 1890; Rev. Ent., 9: 110; Raffray, 894, ibid., 8: 230; Raffray, 1904, Ann. Soc. ent. Fr., 73: 6; Raffray, 1908, Col. Psel., Gen. Ins.: 156; Raffray, 1911, Psel., Coleopt. Cat., 27: 60; Ganglbauer, 1895, Käf. Mitteleurop., 2: 800; Jeannel, 1950, Col. Pscl., Faun. Fr., 53: 349; Besuchet, 1974, Käf. Mitteleurop., 5: 330; Kurbatov, 1989, Psel., In Keys Ident. Ins. Russ. Far East, Vol. 3, Col., Part 1: 352; Newton \& Chandler, 1989, Field. Zool., N. S., (53): 35. Type species: Batrisus formicarius Aubé, designated by Lucas, 1920 (see Newton \& Chandler, 1989).

This genus has not been strictly defined as noted by Newton \& Chandler (1989), and includes four species from Palearctic Region excepting Japan. According to literature, this genus close to the Batristilbus known from Japan in having the large and robust body, similar basal structures of 4th abdominal segment, etc.

\section{Batrisus sibiricus Sharp}

(Fig. 3B)

Batrisus sibiricus Sharp, 1674, Ent. month. Mag., 11: 82; Löbl, 1973, Ann. zool., Warszawa, 30(9):

4; Kurbatov, 1989, Psel., In Keys Ident. Ins. Russ. Far East, Vol. 3, Col., Part 1: 352

Batrisus conophthalmus Reitter, 1887, Deutsch. ent. Zeitschr., 31: 265; Raffray, 1904, Ann. Soc.ent. Fr., 73: 79; Raffray, 1908, Col. Psel., Gen. Ins.: 157; Raffray, 1911, Pscl., Coleopt. Cat., 27: 60; Besuchct, 1979, Rev. suisse Zool., 86(1): 283 (=sibiricus).

Remarks. This species is allied to the European species, B. formicarius Aubé according to Sharp, 1874. This is the first report from South Korea and the most southern record of this species.

Biological notes. Two individuals are captured from the nest of the ant, Lasiusniger (Lin- 
naeus) inhaviting in the rotten wood.

Distribution. South Korea, North Korea, China, Russia (Primorskii, Amur, Siberia).

Specimens esamined: 2 males, Kwangnung, Pochon Gun, Kyonggi Do, 14-19. v. 1992, S. Nomura ieg.

\section{Genus Batrisodes Reitter}

Batrisodes Reitter, 1882a, Deutsch. Ent. Zeitschr., 26: 134; Reitter, 1882b, Verh. naturf. Ver. Briinn, 20: 20.5; Ganglbauer, 1895, Käf. Mitteleurop., 2: 801; Raffray, 1903, Ann. hist.-nat. Mus. nat. Hung., 1: 45; Raffray, 1904, Ann. Soc. ent. Fr., 73: 127; Raffray, 1908, Col. Psel., Gen. Ins.: 157; Raffray, 1911, Psel., Coleopt. Cat., 27: 60; Jeannel, 1950, Col. Psel., Faun. Fr., 53: 351; Jeannel, 19.58, Mém. Mus. nat. Hist., Paris (A), 18(1): 14; Park, 1951, Geol. Surv. Alabama, Mus. Pap., 31: 12; Besuchet, 1974, Käf. Mitteleurop., 5: 331; Kurbatov, 1989, Psel., In Keys Ident. Ins. Russ. Far East, Vol. 3, Col., Part 1: 352; Newton \& Chandler, 1989, Field. Zool., N. S., (53): 34. Type species: Batrisus delaportei Aubé, designated by Lucas, 1920.

Alytus Hampe, 1863, Wien. ent. Monatschr., 7: 286.

This holarctic genus is defined by having the longitudinally striate pronotum and the almost symmetrical median lobe of aedeagus with the very broad and quadrangular basal foramen. The symmetrical aedeagus is however, apparently a plesiomorphic character. Newton \& Chandler, 1989 listed eight subgenera of this genus, three of which, Batrisodes, Excavodes and Pubimodes are known from East Asia.

\section{Subgenus Excavodes Park}

Excavodes Park, 1951, l. c.: 12; Jeannel, 1958, l. c.: 14; Newton \& Chandler, 1989, 1. c.: 34. Type species: Batrisus frontalis LeConte, by original designation.

This subgenus is known from Nearctic and Oriental Regions; eight species were described from Japan. It is characteristic to have the variously modified carina in the frontal groove between the frons and the clypeus in male.

\section{Batrisodes baejeongdoki sp. nov.}

(Figs. 2, 3C)

Male. Length $2.1 \mathrm{~mm}$. Width $0.8 \mathrm{~mm}$.

Body reddish brown to dark brown, elongate and thick, weakly broadened posteriorly.

Head as long as wide, round and thick, clypeus arcuately expanded anteriorly, weakly limbate, frons suddenly convex, densely punctate, vertex slightly convex, with a pair of large dorsal tentorial pits and a median longitudinal carina in posterior half of the head, tempora slightly rounded, covered with long suberect hairs. Eyes small and ovoid, composed of about 20 facets each. Antennae reaching posterior margin of pronotum, moniliform, 1st segment very thick, weakly flattened on antero- 


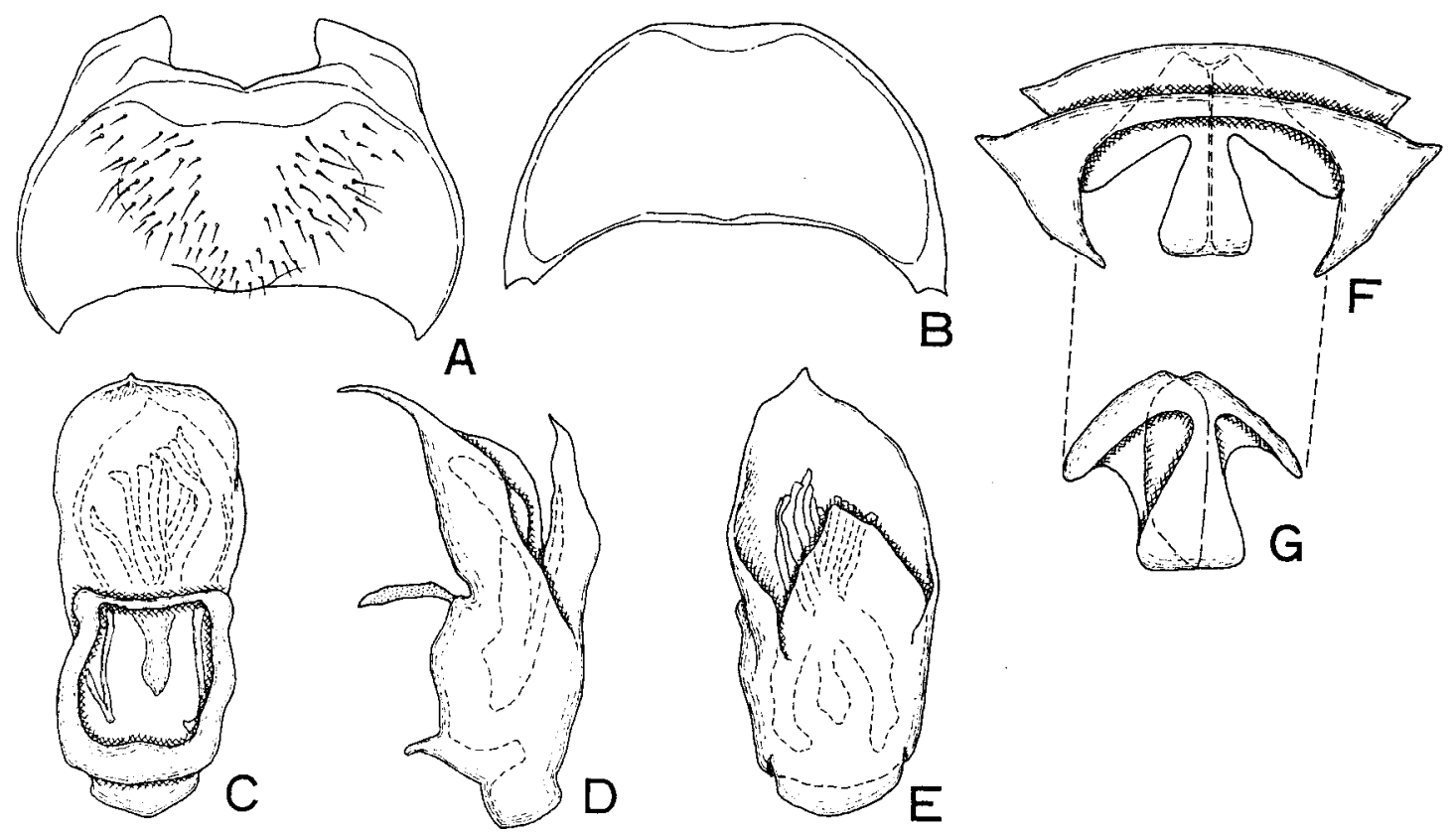

Fig. 2. Batrisodes baejeongdoki sp. nov. A, C-E: male; B, F-G: female. A-B: 8th abdominal sternite; $\mathrm{C}$ : male genitalia in ventral view; D: ditto, in lateral view; E: ditto, in dorsal view; F: 9th sternite and genital plate; G: genital plate.

dorsal side, 2nd segment ovoid, 3rd to 8th subequal in length, each subglobose, 9th to 10th thick and transverse, 11th largest, ovoid, pointed at apex; relative length (width) of each segment from base to apex: 2.0 (1.8): 1.3 (1.1): 1.1 (1.0): 1.0 (1.0): 1.0 (1.0): 1.0 (1.0): 1.1 (1.1): 1.0 (1.0): 1.3 (1.5): 1.5 (1.8): 3.5 (2.3).

Pronotum slightly wider than long, subglobose with a median longitudinal sulcus, a pair of lateral sulci, 2 pairs of dorsal spines and 2 pairs of antebasal foveae, fore pair of the dorsal spines located at anterior $1 / 4$, crooked posteriorly, hind pair at posterior $1 / 3$, acute and curved posteriorly. Elytra weakly convex, wider than long, sparsely punctate, each elytron with 3 basidorsal foveae and 2 longitudinal sulci, outer sulcus running from the most external fovea to the middle of clytron. Legs elongate, hind tibiae slender, each densely covered with hairs in posterior $2 / 5$ with a short pencil.

Abdomen slightly wider than elytra, rounded posteriorly, 4th segment largest, with a pair of short basimedian carinae, a pair of lateral carinae and 2 pairs of basidorsal foveae, lateral carinae divergent, each running from outer basidorsal fovea to posterolateral comer of the segment, 5 th to 6th short, subequal in length, 7th 1.3 times as long as 6th, 8th tergite narrowed posteriorly and convex, 8th sternite semicircular, depressed at the middle with many short setae around the depression. Male genitalia almost symmetrical at basal part; parameres reduced to a small membrane; median lobe bilobate at apical part, basal foramen quadrangular, basal bulb with a basidorsal cham- 

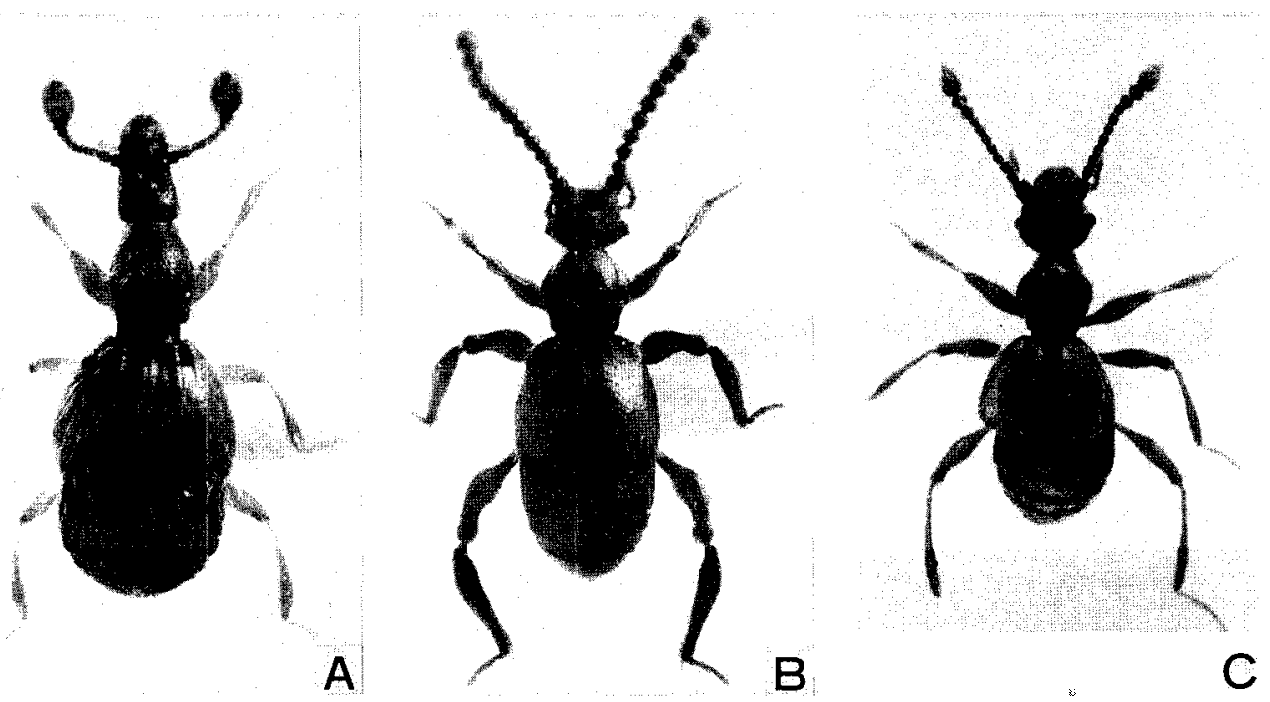

Fig. 3. Dorsal aspects. A: Philoscotus coreanus sp. nov., female; B: Batrisus sibiricus Sharp, male; C: Batrisodes baejeongdoki sp. nov., male.

bcr and a well-developed basiventral projection, ventroapical lobe broad at basal part, narrowed apically and acuminate at apex, dorsoapical lobe shorter than the ventroapical one, triangular in dorsal view, acute at apex; endophallus large and strongly sclerotized, consisting of some elongate spines which is confluent at basal part, divergent in apical part.

Female. Length $2.0 \mathrm{~mm}$. Width $0.8 \mathrm{~mm}$. Very similar to male, but the 8th abdominal sternitc semicircular and slightly convex at middle part. Female genitalia composed of 9th sternite and genital plate, 9th stcrnite broadened apically, deeply cmarginatc on posterior margin, genital plate T-shaped in ventral view, median wall ovoid in lateral view.

Distribution. South Korea (Mt. Chili-san).

Holotypc, male, Samjeong Ri, Macheong Myeon, Namwon Gun, Jeongla-buk Do, 11 v. 1991, S. Nomura leg. Paratypes, 1 female, same locality as holotypc, 14. vii. 1991, S. Nomura leg.; 1 female, Simwon vall., Samnae Myeon, Namwon Gun, Jeongla-buk Do, 13. v. 1991, S. Nomura leg.

Remarks. The new species B.baejeongdoki is similar to the Japanese species, B.dorsalis Jeanne1 and B.stipes (Sharp) in having the coarsely and densely punctate head. But it is very distinct in this genus by the ventrally extended and the acuminate median lobe of the aedeagus.

Etymology. The species name is dedicated to the entomologist, Mr. Jeong Dok Bae for his assistance to our study and this project in various ways.

Genus Basitrodes Jeanne1 
Basitrodes Jeanne], 1958, Mém. Mus. nat. Hist., Paris, 18(1): 26; Kurbatov, 1989, Psel., In Keys Ident. Ins. Russ. Far East, Vol. 3, Col., Part 1: 353; Newton \& Chandler, 1989, Field. Zool., N. S., (53): 33. Type species: Batrisusvestitus Sharp, by original designation.

The genus Basitrodes is not well-defined by Jeannel, 1958, as shown in the previous key. This genus is closely allied to the genera Petaloscapus, Batrisodellus and Batrisodes. Nine species of this genus known from Japan are divided into two groups, vestitus- and palpalis-groups by Jeannel, 1958.

\section{A Key to the Species of the Genus Basitrodes from South Korea}

1. Body definitely constricted at base of 4 th abdominal segment ................myrmecophilus sp. nov.

- Body scarcely constricted

2. Pronotum distinctly longer than wide leptothorax Nomura \& Lee (Chejudo Is.)

- Pronotum about as long as wide or transverse ...3

3. Body larger, 11th antennal segment elongate sp. indet. 1

- Body smaller, 11th antennal segment ovoid sp. indet. 2

\section{Basitrodes myrmecophilus sp. nov.}

(Figs. 4A-D, 5A)

Male. Length 2.4-2.5 mm. Width 0.8-0.9 mm.

Body reddish brown to dark brown and shiny, elongate and very thick.

Head slightly longer than wide, nearly ovoid in dorsal view, clypeus projected anteriorly at median margin, with a Y-shaped carina at middle, frons shallowly concave, with a pair of arcuatc carinae, each carina running from the middle of the concavity to outside of dorsal tentorial pit, vertex strongly convex, with a median longitudinal carina from the middle to hind margin and a pair of large dorsal tentorial pits, tempora large and weakly rounded and covered with long hairs. Eyes large, ovoid and strongly convex, each composed of about 45 facets. Antennae thick, reaching basal margin of elytra, 1st segment subcylindrical, with 2 projections on inner and outer sides, 2nd to 10th segments moniliform, 11th largest and ovoid, relative length (width) of segments from base to apex : 1.1 (0.9): 1.0 (0.7): 1.0 (0.7): 1.0 (0.7): 1.0 (0.7): 1.0 (0.7): 0.9 (0.7): 0.8 (0.7): 1.2 (1.0): 1.2 (1.1): 2.3 (1.3). Maxillary palpi large and elongate, 1st segment short, 2nd elongate and thickened distally, 3rd short and subcylindrical, 4th largest, slightly longer than 2nd, widest at apical 2/5, narrowed in basal part.

Pronotum subglobose, slightly longer than wide, with a median longitudinal, a basimedian and a pair of basilateral sulci, 3 pairs of dorsal spines, a pair of dorsal longitudinal carinae and a pair of lateral foveae, median longitudinal sulcus running from anterior $1 / 10$ to posterior $1 / 3$, basimedian sulcus shallow and T-shaped, each basilateral sulcus running from lateral fovea to dorsal carina, dorsal spines located at anterior $1 / 3$, posterior $2 / 5$ and $1 / 4$, each dorsal carina connected with mid and hind dorsal spines. Elytra wider than long, broadened posteriorly, widest at posterior 1/3, convex and covered with sparse and long pubescence. Legs long and thick, hind trochanters short, each with an incurved spine on posterior side. 
Abdomen constricted at both basal sides, 4th segment largest, slightly narrower than elytra, with a pair of oblique dorsolateral carinae and a pair of short dorsomedian carinae, each dorsolateral carina reaching posterolateral comer of the segment, dorsomedian carinae subparallel to each other, each located in basal $1 / 4,5$ th and 6th segments short, 7th longer than 5th, narrowed posteriorly, 8th tergite transverse and convex, 8th sternite nearly semicircular, weakly concave at median part.

Male genitalia strongly sclerotized and asymmetrical, parameres paird, lamellar and almost membranous, median lobe broadened distally, with a large basal foramen, ventral stalk and a dorsal apophysis (see remarks), ventral stalk very broad at basal part, narrowed distally and curved leftward, dorsal apophysis elongate, narrowed distally and arcuately curved internally, articulated with a process of basal bulb on its left side, internal sac membranous, with 3 large transverse sclerites between ventral stalk and dorsal apophysis.

Female. Length 2.4-2.5 mm. Width 0.8-0.9 mm. Very similar to male without the following characters: hind trochanters without spine, 9th abdominal sternite transverse, weakly sclerotized on basal part, genital plate T-shaped in posterior view.

Distribution. South Korea (Kyonggi Do).

Holotype, male, Kwangnung, Pochon Gun, Kyonggi Do, 14-19. v. 1992, S. Nomura leg. Paratypes, 7 males 7 females, same data as holotype.

Remarks. The new species B. myrmecophilus is classified into the vestitus-group of this genus by having the bispiniculate first antenna1 segment after Jeannel, 1958. But it differs from the other species by the clypeus with a Y-shaped carina and the structure of the male genitalia.

The male genitalia of this species is similar to that of the Batrisocenus-complexsensu Nomura, 1991 in having an independent and movable dorsal apophysis. This organ of the Batrisocenuscomplex is formed from the sclerite of the wall of the median lobe and the membrane of its internal sac without exception as far as we know, whereas the dorsal apophysis of this new species is merely a sclerite separated from the internal sac. Therefore, the dorsal apophysis of this species is not homologous with that of the Batrisocenus-complex. Such structure might be evolved in some groups in parallel because of the same copulatory function.

Biological notes. The type specimens of this species were captured from the colonies of the ants, Brachyponera chinensis Emery nested in rotten woods.

Basitrodes sp. indet. 1

(Fig. 5B)

Distribution. South Korea (Namhaedo Is.).

Specimen examined: 1 female, Lidong Myeon, Namhaedo Is., Kyongsang-nam Do, 19. vii. 1991, S. Nomura leg.

Remarks. Only one female obtained is indeterminate owing to the lack of the any feature to characterize it as a new species. But this is classified into the palpalis-group by the small first segment of antenna. 
Distribution. South Korea (Kyonggi-do).

Specimen esamined: 1 female, Kwangnung, Pochon Gun, Kyonggi Do, 14-19. v. 1992, S. Nomura leg.

Remarks. This indeterminate species is very similar to B. myrmecophilus sp. nov., but is different by the small body without constriction between the metathorax and abdomen.

Biological notes. The only individual of this species was found from a nest of an ant, Lasius flavus (Fabricius) inhabited under stone.

\section{Genus Batriscenellus Jeanne1}

Batriscenellus Jeannel, 1958, Mém. Mus. nat. Hist., Paris (A), 18(1): 60; Kurbatov, 1989, Psel., In Keys Ident. Ins. Russ. Far East, Vol. 3, Col., Part 1: 354. Type species: Batrisus fragilis Sharp, by original designation. (see Nomura \& Lee, 1992 for historical review.)

\section{A Key to the Species of the Genus Batriscenellus from South Korea}

1. Fifth abdominal segment with a fringe of bold setae at median part of its hind margin in male; sixth segment deeply excavated at anteromedian part with secretory setae on its bottom (subgenus Batriscenellus s. str.); male genitalia with dorsally projected basal bulb and the gently narrowed ventral stalk on the median lobe vicurius Löbl

- Fifth to 6th abdominal segments flat on median part, without excavation nor secretory setae in male; hind femora slender, gently narrowed at apical part in male (subgenus Coreoscenellus nov.) brachygaster sp. nov.

\section{Subgenus Batriscenellus s. str.}

This nominotypical subgenus was redefined by Nomura, 1991 based on the following two characters: the sexual patch constituted of a pair of setifcrous patches on fifth segment, a fringe made of bold setae on the fifth segment, and the large and deep excavation including secretory setae on the sixth; and the basal bulb of the male genitalia with a well-projected articulate process.

\section{Batriscenellus vicarius Löbl}

Batriscenellus jupotzicus vicarius Löbl, 1973, Ann. Zool., Warszawa, 30(9): 322; Kurbatov, 1989, Psel., In Keys Ident. Ins. Russ. Far East, Vol. 3, Col., Part 1: 354; 1990, Rev. Ent. URSS, 69(1): 75; Nomura, 1991, Esakia, Fukuoka, (31): 302.

Batriscenellus vicurius : Nomura \& Lee, 1992, Esakia, Fukuoka, (32): 61.

Distribution. South Korea (including Chejudo Is.), North Korea, Russia (Primorskii) and Japan (Tsushima Is.) 
Specimens examined: 32 males 27 females, Kwangnung, Pochon Gun, Kyonggi Do, 14-19. v. 1992, S. Nomura leg.; 1 female, same locality as above, 17. vii. 1992, S. Nomura leg.; 1 male 2 females, Pupan Myon, Hongcheon Gun, Kanweon Do, 20. v. 1992, S. Nomura leg.; 3 males 6 females, same locality as above, 22. vii. 1992, S. Nomura leg.; 1 male, Bougmyong Ri, Chunchon Gun, Kangweon Do, 22-23. v. 1992. S. Nomura leg.

Remarks. This species is distributed in broad area including two islands, Chejudo, Korea and Tsushima, Japan, and clearly separated from the ranges of B. japonicus (Sharp) and allies.

Subgenus Coreoscenellus nov.

Type species: Batriscenellus brachygaster sp. nov.

The new subgenus Coreoscenellus is easily distinguished from the subgenera Batriscenellus, Scaioscenellus and Nipponoscenellus by lacking sexual patch on the fifth to sixth abdominal segments in male. It resembles the subgenus Batriscenellinus Nomura in having the short and simple abdomen, but the hind femora are normal without setiferous patch.
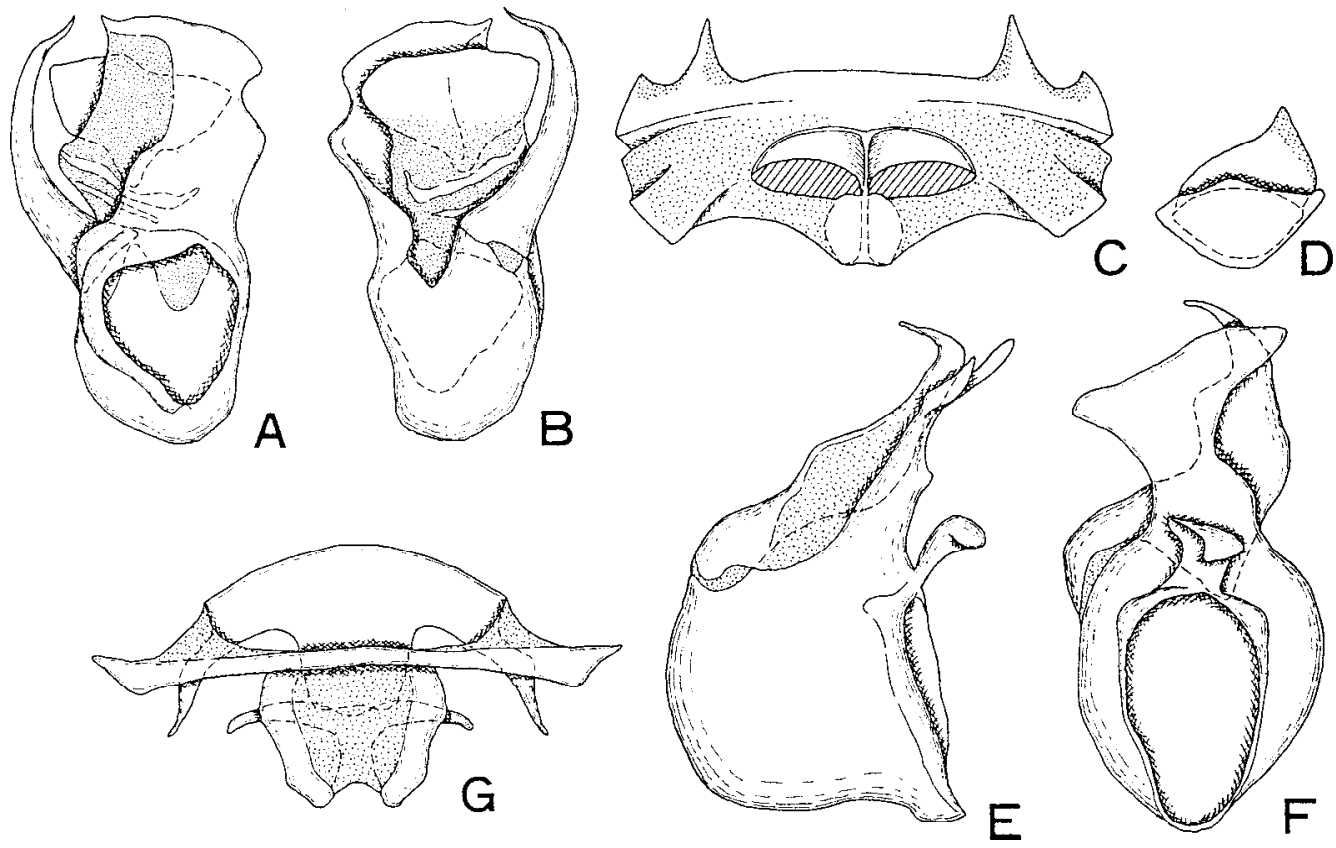

Fig. 4. A-D: Basitrodes myrmecophilus sp. nov.; E-G: Batriscenellus brachygaster sp. nov. A: male genitalia in ventral view; B: ditto, in dorsal view; C: female, 9th abdominal sternite and genital plate; D: male 9th sternite; E: male genitalia in lateral view; F: ditto, in ventral view; G: female 9th sternite and genital plate. 

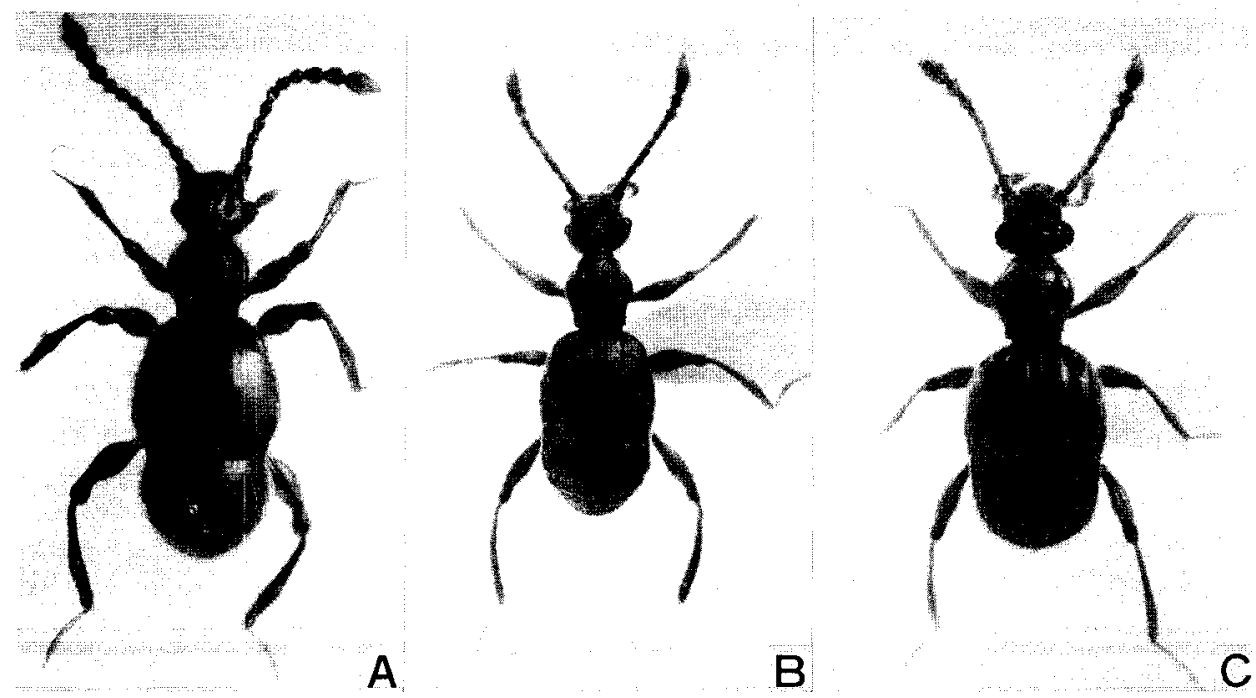

Fig. 5. Dorsal aspects. A: Basitrodes myrmecophilus sp.nov.; B: B. sp. indet. 1; C: Batriscenellusbrachygaster sp. nov.

\section{Batriscenellus brachygaster sp. nov.}

(Figs. 4E-G, SC)

Male. Length $1.8 \mathrm{~mm}$. Width $0.6 \mathrm{~mm}$.

Body reddish brown to light brown, elongate and thickened in elytra and abdomen.

Headlonger than wide, subparallel-sided, clypeus short and arcuately expanded anteriorly, frons weakly depressed and sparsely punctate, with a transverse sulcus, vertex weakly convex, minutely punctate and shiny, with a fine longitudinal carina and a pair of small dorsal tentorial pits, tempora narrow and rounded. Eyes each large and ovoid, composed of about 25 facets. Antcnnac slender, reaching base of elytra, 1st segment short and subcylindrical, with a conical trichome on extcrnalside, 2nd subcylindrical, 3rd to 8th each ovoid, 9th to 10th thick and ovoid, subequal in length, 1 lth largest and ovoid; relative length (width) of each segment from base to apex: 1.2 (1.5): 1.2 (0.8): 1.0 (0.7): 0.8 (0.6): 1.0 (0.7): 0.9 (0.6): 1.1 (0.8): 0.9 (0.7): 1.3 (1.0): 1.3 (1.1): 2.5 (1.6).

Pronotum as long as wide, round-sided, minutely punctate and shiny, with a median longitudinal sulcus a pair of lateral sulci, a V-shaped transverse sulcus at posterior $1 / 4$ to $1 / 5$, a pair of lateral foveae and 2 pairs of antebasal foveae, each lateral sulcus and transverse sulcus connected to each other at each lateral fovea at posterior $1 / 4$ on both sides. Elytra wider than long, quadrangular and convex with expanded humeri, each clytron with 2 basal foveae and 2 sulci, outer sulcus running from outer basal fovea to posterior 1/6. Legs elongate, thickened in femora.

Abdomen subparallel-sided on basal part, suddenly narrowed in posterior $1 / 3,4$ th segment largest and subcylindrical, with a pair of basimcdian carinae in basal $1 / 3$, 5th to 6th very short, subequal in length, 7th large, 2.5 times as long as 6 th, 8 th tergite transverse, arcuate on posterior 
margin, 8th sternite semicircular, weakly flattened at median part, 9th sternite very small, triangular in external view. Male genitalia consisting of small and membranous parameres, large median lobe and well-sclerotized dorsal apophysis, median lobe bulbous, apical spine strongly broadened apically, dorsal apophysis elongate, narrowed and sharpened distally, curved ventroapically in the apical part.

Female. Length 1.8-1.9 mm. Width 0.6-0.7 mm. Very similar to male, but eyes smaller and abdomen longer. Female genitalia composed of 9th sternite and genital plate, 9th sternite transverse, fore lobe membranous in median part, strongly sclerotized on both sides, hind lobe broad and Tshaped, with transverse elongate sclerite at basiventral part, genital plate T-shaped in ventral view.

Distribution. South Korea.

Holotype, male, Iidong Ri, Namhaedo Is., Kyongsang-nam Do, 19. vii. 1991, S. Nomura leg. Paratypes,, 1 male 13 females, same data as holotype; 1 male, Naelyeong Ri, Samnae Myeon, Cheonla-buk Do, 13. vii. 1991, S. Nomura leg.

Remarks. This species B. brachygaster is distinct in this genus in lacking sexual patch or any clear male feature. But the male of this species is distinguished from the female by the large eyes, the shortened fifth to eighth abdominal segments and the exposed ninth abdominal sternite.

\section{Subfamily GONIACERINAE Reitter}

\section{Tribe Iniocyphini Park}

This tribe had ever been called Tanypleurini Jeanne1 until Newton \& Thayer (1992) gave the new trival name because of the homonymy of the type genus Tanypleurus Raffray. The subtrival name is therefore, also emended to Natypleurina for the new genus name Natypleurus.

\section{Subtribe Natypleurina Newton \& Thayer}

\section{A Key to the Genera of the Subtribe Natypleurina from South Korea}

1. Body strongly convex, head smaller than pronotum, 11th antenna1 segment with a cylindrical nodule on dorsal side in male ............................................................ Triomicrus Sharp

- Body weakly convex, head wider than pronotum, with a large excavation and a pair of setiferous patches in male .................................................................................. 2

2. Antennae slender, 2nd to 8th antennal segments subcylindrical ........... Nipponobythus Jeanne1

- Antennae moniliform and each twisted in the middle part . . . . . . . Machulkaia Löbl (Chejudo Is.)

Genus Nipponobythus Jeanne1

Nipporzobythus Jeannel, 1958, Mém. Mus. nat. Hist., Paris (A), 18(1): 77; Löbl, 196.5, Ann. nat. 
Mus. Wien, 68: 491; Newton \& Chandler, 1989, Field. Zool., N. S., (53): 51. Type species:

Nipponobythus syrbatoides Jeannel, by original designation.

This genus was established by Jeannel, 1958 and revised by Löbl, 1965 on the Japanese and Chinese faunae. Eleven species are known from those countries up to now. It is closely allied to the Japanese genera, Takaorites Jeanne1 and Bythiotes Jeanne1 (see Newton \& Chandler, 1989 for homonymy), but separated from the former by elongate and subcylindrical third to eighth segments of antenna (ovoid or subglobose in Takaorites), and from the latter by the deeply excavated frons (shallowly sculptured and setose in Bythiotes).

\section{Nipponobythus longicornis sp. nov.}

(Figs. 6A, C-F, 7A)

Male. Length $1.8 \mathrm{~mm}$. Width $0.8 \mathrm{~mm}$.

Body reddish brown, broadened in head, elytra, and abdomen.

Head large and transverse, clypeus short, arcuate, frons very broad, with large median concavity
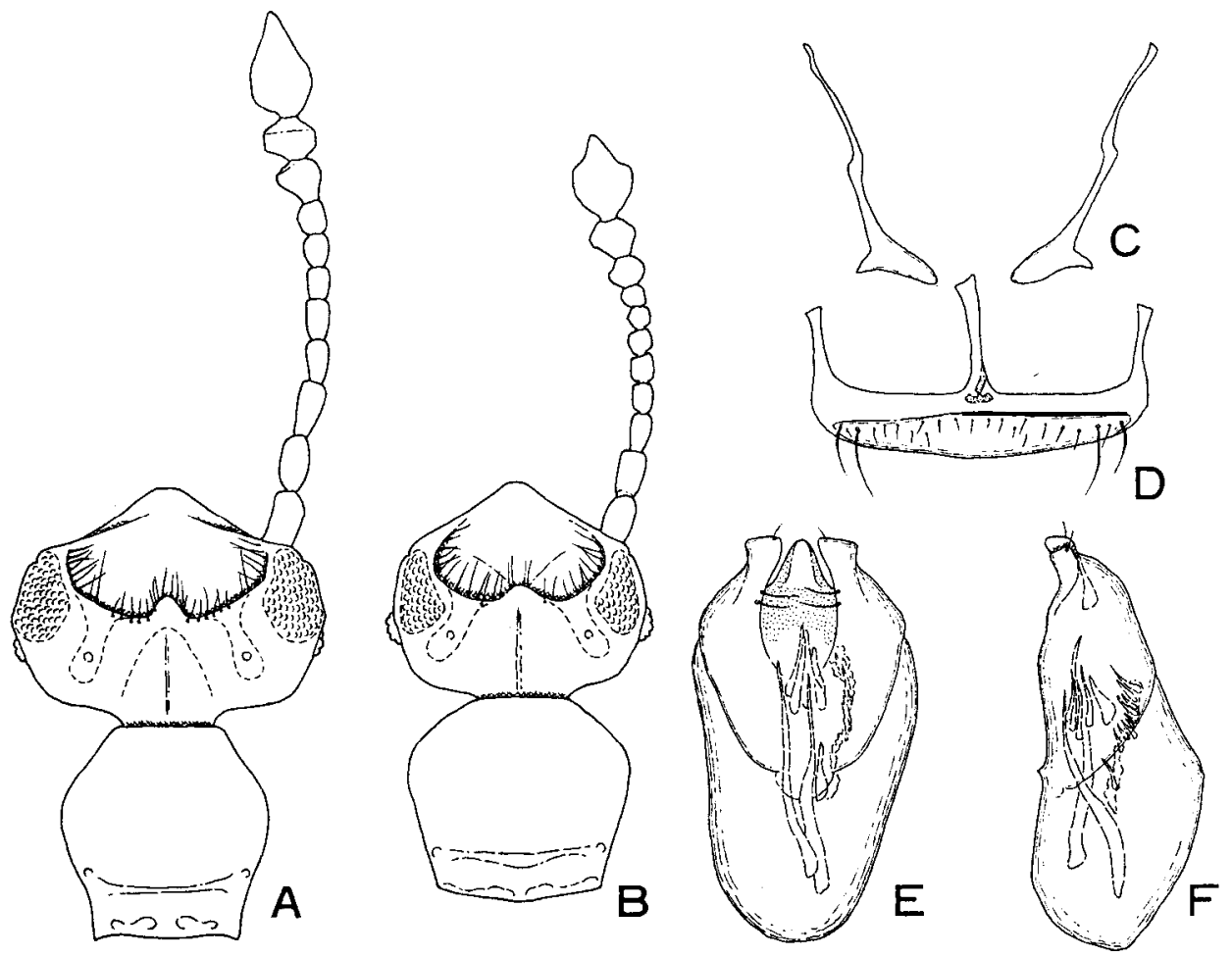

Fig. 6. A, C-F: Nipporzobythus longicornis sp. nov.; B: N.omissus Löbl. A-B: heads and pronota; C: 9th abdominal sternite; D: 8th tergite; E: male genitalia in ventral view; $\mathrm{F}$ : ditto, in lateral view. 
and a pair of flat setiferous patches on dorsolateral sides, median concavity transverse, reaching posterior $3 / 7$ of head, with long hairs on posterior margin, each setiferous patch elongate ovoid, located on posterolateral side of median concavity, vertex shallowly depressed on median part, with a pair of large dorsal tentorial pits, postgenae broad and rounded. Eyes partially visible in dorsal view, large and ovoid, each composed of about 45 facets. Antennae slender, reaching base of elytra, 1st segment subcylindrical, 2nd ovoid, 3rd to 8th each sybcylindrical and elongate, 9th to 10th thick, weakly subglobose, 11th largest and ovoid, pointed at apex, relative length (width) of each segment from base to apex: $1.8(1.2): 1.5$ (1.0): $1.3(0.8): 1.1$ (0.7): $1.0(0.7): 1.2(0.7): 1.0(0.7): 1.0$ (0.7): 1.3 (1.2): 1.2 (1.3): 3.0 (1.8).

Pronotum slightly wider than long, round-sided, weakly convex, minutely punctatc and shiny, with a shallow transverse sulcus at posterior 1/4. Elytra wider than long, broadened posteriorly and convex, humeri weakly expanded, each elytron with 2 foveae and 2 shallow sulci. Legs elongate, hind tibiae slender, curved internally and thickened in apical 1/3.

Abdomen slightly narrower than elytra, 4th segment largest, subparallel-sided, with a pair of fine and short dorsomedian carinae and a pair of elongate paratergites, 5th to 7th each short, subcqual in length, 8th tergite transverse and short, 8th sternite E-shaped, median stalk slender and slightly broadened anteriorly and weakly curved rightward, longer than each lateral stalk, hind part appeared externally, transverse and pubescent, 9th sternitc consisting of a pair of elongate and thin sclcrites, each sclerite broad and laterally projected in apical part, narrowed and slightly curved internally in basal part, its base connected with the basal terminal of each lateral stalk of 8th sternite.

Male genitalia weakly sclerotized and ovoid; parameres symmetrical, almost fused with median lobe, each paramere widest at the middle, narrowed and projected ventroapically, truncate with a small seta at apex; median lobe bulbous, membranous with a small triangular sclcritc at apex; cndophallus composed of 2 long and many short spines, long spines each bold at base, acuminate apically, short spines located at apical part and right side of the long spines.

Female. Unknown.

Distribution. South Korea (Mt. Chilisan).

Holotype, male, Samjcong Ri, Macheon Myeon, Namweon Kun, Chcongla-buk Do, 14. vii. 1991, S. Nomura leg.

Remarks. The new species, N. longicornis is very close to N. omissus Löb] (Fig. 6B) described from Western Kyushu, Japan, but first to third segments of antennae arc longer and slenderer, the cranium has a pair of weak lateral expansions and the pronotum is narrower.

\section{Genus Triomicrus Sharp}

Triomicrus Sharp, 1883, Trans. ent. Soc. London, 1883, p. 325. Type species: Bryaxis protervis Sharp, designated by Lucas, 1920. (see Nomura \& Lee, 1992 for synonymy.)

\section{Triomicrus penicilatus Nomura \& Lee}

(Fig. 7B) 
Triomicrus penicilatus Nomura \& Lee, 1992, Esakia, Fukuoka, (32): 64.

Distribution. South Korea (including Chejudo Is.).

Specimens examined: 3 males, Naelyong Ri, Samnae Myeon, Cheongla-buk Do, 16. vii. 1991, S. Nomura leg.

Remarks. This species is very similar to T. sublaevis Raffray in having the sparsely punctate pronotum and the long hind legs. But it differs from the latter by the longer right plate of the ninth sternite than the left (the left plate is longer than the right in T. sublaevis).

Tribe Brachyglutini Raffray

Subtribe Brachyglutina s. str.

\section{A Key to the Genera of the Subtribe Brachyglutina from South Korea}

1. Pronotum subglobose and glabrous on dorsal surface, with a basimedian fovea; each elytron with 2 basal foveae or shallow depressions Batraxis Reitter

- Pronotum wider than long, punctate and pubescent on dorsal surface, with a basimedian and a pair of lateral foveae; each elytron with 3 basal foveae

2. Pronotum with a transverse sulcus between basimedian and lateral foveae ... Rybaxis Saulcy

- Pronotum without transverse sulcus Trissemus Jeanne1

\section{Genus Batraxis Reitter}

Batraxis Reitter, 1881, Verh. Kais.-Königl.zool.-bot. Ges. Wien, 31: 464; Raffray, 1895, Rev. Ent., 14: 21; Raffray, 1904, Ann. Soc. ent. Fr., 73: 109; Raffray, 1908, Col. Psel., Gen. Ins.: 200; Raffray, 1911, Psel., Coleopt. Cat., (27): 77; Besuchet, 1969, Rev. suisse Zool., 76(2): 412; Kurbatov, 1989, Psel., In Keys Ident. Ins. Russ. Far East, Vol. 1, Col., Part 1: 358; Newton \& Chandler, 1989, Field. Zool., N. S., (53): 46. Type species: Batraxis hatnpei Reitter, by monotypy.

Batrisomorpha Raffray, 1882, Rev. Ent., 1: 38. Type species: Bryaxis armitagei King, designated by Newton \& Chandler, 1989.

Batraxys Raffray, 1900, Proc. Linn. Soc. N. S. Wales, 25: 147 (misspelling).

Raffrayella Blattny, 1925, Sbom. Ent. Odd. Narodn. Mus. Praze, 3: 204. Type species: Raffrayella raffrayana Blattný, by monotypy.

Balkanella Karaman, 1967, Bull. Soc. ent. Mulhouse, 60 (preoccupied by S. Karaman, 1933); Besuchet, 1969, 1. c.: 412 (=Batraxis ); Newton \& Chandler, 1989, 1. c.: 6 


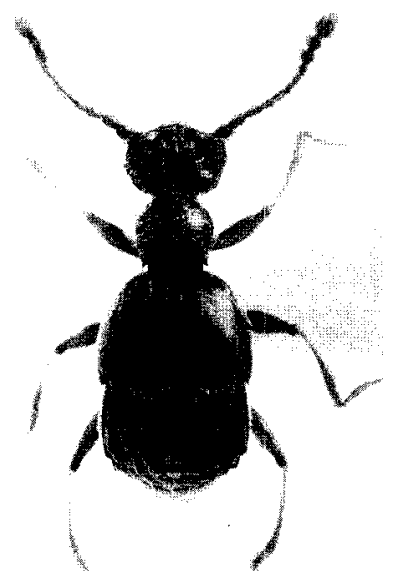

A

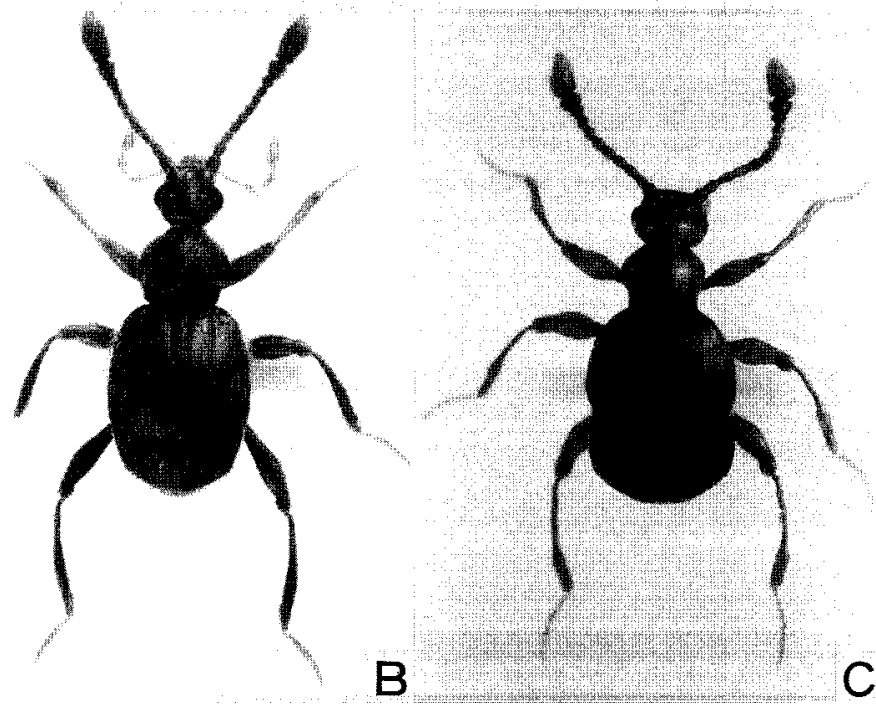

Fig. 7. Dorsal aspects. A: Nipponobythus longicomis sp. nov., male; B: Triomicrus penicilatus Nomura \& Lee, male; C: Batraxis splendida Nomura, male.

Batraxis splendida Nomura, 1986, Kontyti, Tokyo, 54(3): 501; 1989a, Col. Psel., Ch. L. Jap. Ins., Fukuoka, 1: 290.

Distribution. South Korea (Kyonggi Do), Japan (Ryukyus).

Specimens examined: 10 males 8 females, Kwangnung, Pochon Gun, Kyonggi Do, 14-19.v. 1992, S. Nomura leg.

Remarks. This species is only known from lriomotc Is., Ryukyus, Japan, and is recorded from the continent for the first time.

Biological notes. This species was captured from the nest of the ant, Brachyponerachinensis Emery, in the same condition as on Iriomote Is.

\section{Genus Rybaxis Saulcy}

Rybaxis Saulcy, 1876, Bull. Soc. Hist. nat. Metz, 13: 96; Rcittcr, 1881, Verh.Kais.-Königl.zool.bot. Ges. Wien, 31: 464; Reitter, 1882b, Verh. naturf. Ver. Brünn, 20: 190; Raffray, 1890, Rev. Ent., 9: 118; Raffray, 1897, Trans. S. Afr. phil.Soc., 10: 88; Raffray, 1900, Proc. Linn. Soc. N. S. Wales, 25: 149; Raffray, 1904, Ann. Soc. cnt. Fr., 73: 116; Raffray, 1908, Col. Psel., Gen. Ins.: 246; Raffray, 1911, Psel.,Coleopt. Cat., (27): 106; Jeannel, 1958, Mém. Mus. nat. Hist., Paris (A), 18(1):95; Besuchct, 1974, Käf. Mittclcurop., 5: 351; Kurbatov, 1989, Psel., In Keys Ident. Ins. Russ. Far East, Vol. 1, Col., Part 1: 357; Newton \& Chandler, 1989, Field. Zool., N. S., (53): 44. Type species: Bryaxis sanguinea Leach, designated 
by Bowman, 1934 .

Bryaxis Leach, 1817, Zool. Misc., 3: 85; Ganglbauer, 1895, Käf. Mitteleurop., 2: 806; Jeannel, 1949, Mém. Mus. nat. Hist., Paris, N. S., 29: 87; Jeannel, 1950, Col. Psel., Faun. Fr., 53: 280; ICZN, 1969, Bull. zool. Nom., 26: 133 (rejected).

\section{Rybaxis lamellifer Löbl}

(Fig. 9A)

Rybaxis lamellifer Löbl, 1973, Ann. zool., Warszawa, 30 (9): 326; Kurbatov, 1989, Psel., In Keys Ident. Ins. Russ. Far East, Vol. 1, Col., Part 1: 357.

Distribution. South Korea (Kangweon Do), North Korea.

Specimen examined: 1 male, Bougmyong Ri, Chunchon Gun, Kangweon Do, 21. vii. 1992, S. Nomura leg.

Remarks. This species is distinct from the other species of this genus in the bifurcate paramerc of the male genitalia and with an inner process of the eleventh segment of the antennae at the basal $1 / 3$.

\section{Genus Trissemus Jeanne1}

Trissemus Jeanncl, 1949a, Mém. Mus. nat. Hist., Paris, N. S., 29: 95; Jcanncl, 1952, Rev. fr. Ent., 19(2): 88; Jeannel, 1957, ibid., 24(1): 22; Jeannel, 1958, Mém. Mus. nat. Hist., Paris (A), 18(1): 99; Jcannel, 1959b, Ann. Mus. r. Congo belge, Tervurcn (Ser. 8, Sci. zool.), 75: 529; Jcannel, 1960, Bull. brit. Mus. (nat. Hist.) Ent., 9(9):438; Jeanncl, 1961, ibid., 10(10): 448; Besuchet, 1974, Käf. Mittelcurop., 5: 357; Kurbatov, 1989, Psel., In Keys Ident. Ins. Russ. Far East, Vol. 1, Col., Part 1: 358; Newton \& Chandler, 1989, Field. Zool., N. S., (53): 44. Type species: Bryaxis antennata Aubé, by original designation.

This genus consists of about $130 \mathrm{spp}$. and is widely distributed in Oriental and Afrotropical regions. It is classified into six subgcncra, Trissemus s. str., Trissemites Jeannel, Trissemellus Jeannel, Trissemodes, Jeannel, Trissemosus Jeanne1 and Trissemidius Jcanncl, after Jcanncl, 1959b, of which the former three subgenera are known from Japan.

\section{Subgenus Trissetnus s.str.}

The nominotypical subgenus is characterized by the narrow basimedian depression of fourth abdominal tergite (about $1 / 5$ times as wide as the tergitc) and the male character of the antennal funicle.

\section{Trissemuspeninsulanrcs sp. nov.}

(Figs. 8, 9B)

Male. Length 1.9-2.0 mm. Width $0.8 \mathrm{~mm}$ 
Body reddish brown to dark brown, shiny, broad and thick in elytra and abdomen.

Head longer than wide, ovoid and minutely punctate on dorsal surface, clypeus arcuately expanded anteriorly, frons weakly depressed on median part with a fovea at middle, vertex slightly convex with a pair of dorsal tentorial pits, postgenae rounded. Eyes well developed, convex and ovoid, each composed of about 30 facets. Antennae elongate, reaching base of elytra, covered with long hairs, 1st segment longer than wide, thick and gently narrowed toward apex, 2nd subcylindrical, longer than wide, 3rd elongate, weakly thickened distally, 4th to 6th each ovoid, successively enlarged, 7th shortest, half as long as 6th, as long as wide, 8th slightly wider than 7th, 9th to 10th transverse, 11th largest, ovoid and conical at apex, with a large process on inner side. Maxillary palpi short and thick, 1st segment very small and tubular, 2nd elongate, suddenly thickened in apical $1 / 3$, 3rd thick and subglobose, 4th largest and ovoid, with a short and slender palpal spine at apex.

Pronotum wider than long, widest at middle, weakly convex on dorsal surface, roundly expanded at both sides, sparsely punctate and covered with short pubescence, with a pair of large lateral foveae and a basimedian fovea. Elytra transverse, weakly narrowed anteriorly, convex on dorsal surface, each elytron with 3 basal foveae and 2 longitudinal sulci, exterior sulcus running from outer fovea to its hind margin. Legs long and robust, fore and mid trochanters short, each with a small denticle on ventral side, hind femora thickened in apical $2 / 3$, weakly projected at apical $2 / 5$, with long hairs on inner side, fore tibiae slender, each with a short denticle at apical $1 / 3$ of its inner side, mid tibiae slender, covered with bold setae in apical $1 / 3$, with a large process at apical $1 / 4$, the process lamellar and broadened apically, obliquely truncate at apex, hind tibiae very long and slender, gently broadened distally and weakly curved internally in apical $1 / 4$, with a short denticle near apex, hind tarsi slender, 2nd segment constricted near the middle.

Abdomen broad, narrowed distally, 4th segment largest and subparallel-sided with a pair of short and parallel basal carinae, 5th to Sth segments successively shortened and narrowed, 8th sternite semicircular and flattened.

Male genitalia consisting of a pair of parameres and median lobe; parameres each reduced to small and semicircular lobe; median lobe large, about twice as long as wide, bulbous at base, narrowed distally, with a transverse basal foramen and a small trapezoid sclerite at apex; endophallus composed of a pair of groups of small spines.

Female. Length 1.7-1.8 mm, Width 0.8 mm. Similar to male, but differs in the following characters: Body smaller, antennae very slender, 7th to 10th segments each subglobose, 11th flattened at inner side. Legs smaller than in male, trochanters and tibiae without denticle nor projection, 2nd segment of hind tarsi slightly thickened distally, 8th abdominal sternite very short, weakly convex.

Distribution. South Korea (Mt. Chilisan).

Holotype, male, Whanjang Ri, Whage Myeon, Cheonla-nam Do, 17. vii. 1991, S. Nomura leg. Paratypes: 1 female, same data as holotype; 1 male 3 females, Haccheong, Samnae Myeon, Cheonla-buk Do, 10. v. 1991, S. Nomura leg.

Remarks. The new species T. peninsulanus is very closed to T.pseudalienus Kurbatov from Kunashir Is., Southern Kuril. But the Korean species is distinguished from the others by the fore tibiae each with a median spine in the internal side and the elongate and apically narrowed male genitalia. 

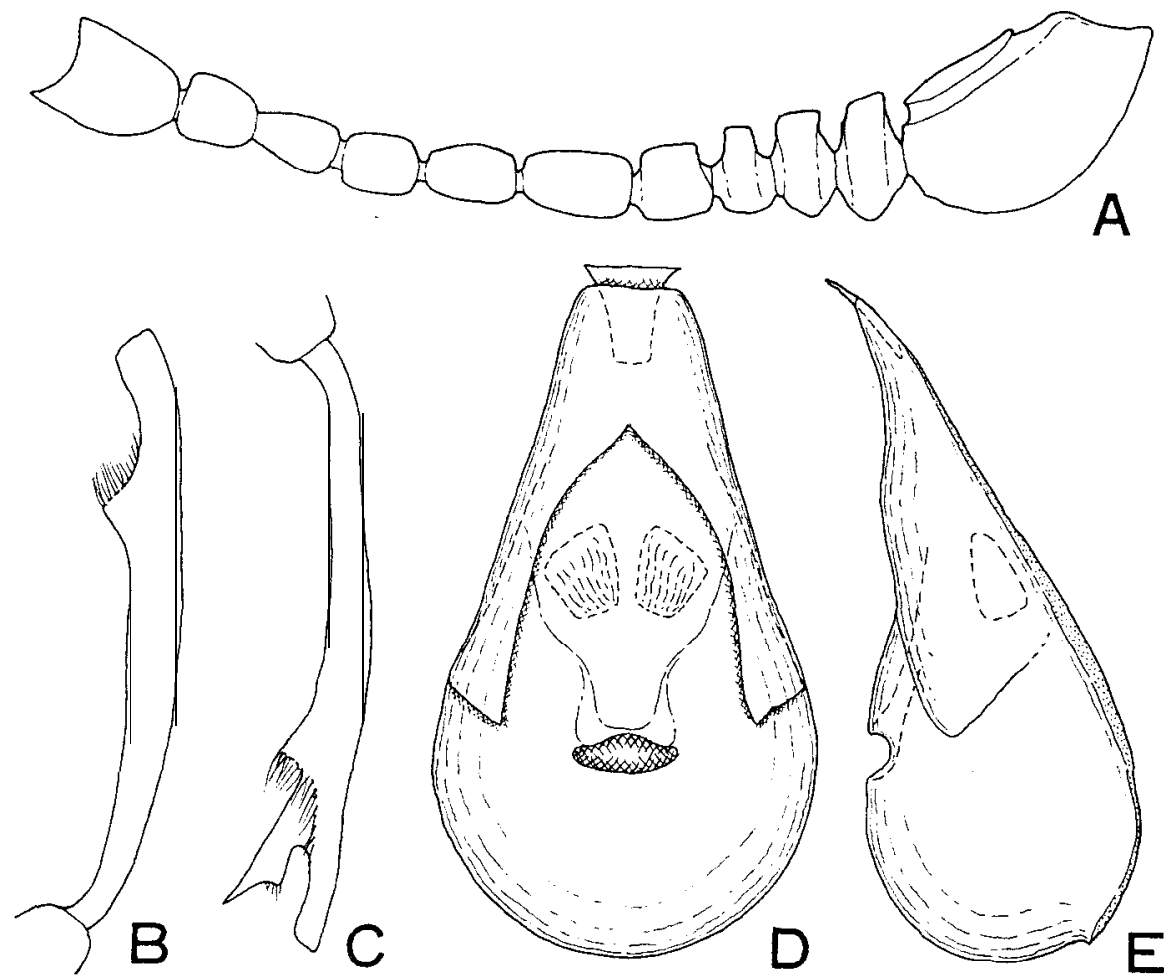

Fig. 8. Trissemus peninsulanus sp. nov., male. A: right antenna; B: fore tibia; B: mid tibia; D: male genitalia in ventral view; E: ditto, in lateral view.

\section{Tribe Bythinini Raffray}

Subtribe Bythinina s. str.

Genus Btyaxis Kugelann

Btyaxis Kugelann, 1794, Neuest. Mag. Lieb. Ent., 1: 580; Kurbatov, 1989, Psel., In Keys Ident. Ins. Russ. Far East, Vol. 3, Col., Part 1: 355. Type species: Pselaphus bulbifer Reichenbach, designated by ICZN, 1969. (see Nomura \& Lee, 1992 for synonymy.)

A Key to the Species of the Genus Bryaxis from South Korea (including Chejudo Is.) 
1. First antenna1 segment subcyrindrical to ovoid, without secretory organ; Second antenna1 segment strongly swollen or carinate in male

- First antennal segment swollen, with a secretory organ in male ... 7

2. Maxillary palpi with 2nd to 3rd segments almost glabrous (subgen. Bythiniama Jeannel) ; antennae with 2nd segment almost subglobose, with well-projected secretory organ at basal $1 / 3$ hallamontanus Nomura \& Lee (Chejudo Is.)

- Maxillary palpi with 2nd to 3rd segments distinctly granulate (subgen Arcobythus Jeannel)

3. Second antenna1 segment arcuately extending internally in male ..............nogodanensis sp. nov.

- Second antennal segment swollen, with a small secretory organ in inner side ............................ 4

4. Second antenna1 segment with a secretory organ at basal part ..................................................5

- Second antennal segment with a secretory organ at apical part ................................................ 6

5. Second antennal segment longer than 1st, 1.7 times as long as wide, without long seta macheonensis sp. nov.

- Second antenna1 segment as long as 1st, 1.3 times as long as wide, slightly flattened on inner side, with a long and suberect seta at basal $1 / 3$ on dorsal side kimjongkuki sp. nov.

6. Second antenna1 segment longer than 1st, strongly swollen and projected internally; pronotum sparsely covered with minute punctures on dorsal surface leechanyoungi sp. nov.

- Second antenna1 segment as long as 1st, 1.5 times as long as wide, swollen and weakly projected internally; pronotum densely covered with coarse punctures on dorsal surface chilimontanus sp. nov.

7. Second antennal segment projected anteriorly on inner side (subgen. Bryaxis s. str.); pronotum with sparse punctures peninsulanus sp. nov.

- Second antenna1 segment small and subglobose (subgen. Bythobletus Reitter); pronotum with dense and coarse punctures coreanus Nomura \& Lec

\section{Subgenus Arcobythus Jeanne1}

Arcobythus Jeannel, 1958, Mém. Mus. nat. Hist., Paris (A), 18(1): 87; Newton, \& Chandler, 1989, Field. Zool, N. S., (53): 47. Type species: Bryaxis frontalis Jeanne1 by original designation. This subgenus is characterized by the swollen second antennal segment and the granulate maxillary palpi. Five species of this subgenus are known from Japan after Jeannel, 1958, but many species from Palearctic region may belong to this subgenus.

\section{Bryaxis nogodanensis sp. nov.}

(Figs. 9C, 10A, H, 11A, B, G)

Heteromorphous male. Unknown.

Homomorphous male. Length $1.6 \mathrm{~mm}$. Width $0.7 \mathrm{~mm}$.

Body reddish brown, tarsi light brown, weakly narrowed anteriorly.

Head slightly longer than wide, gently narrowed anteriorly, clypeus very short, frons concave 
and glabrous on median part, vertex weakly convex, sparsely covered with coarse punctures, with a slight median longitudinal carina and a pair of dorsal tentorial pits, shallowly concave around the tentorial pits, postgenae gently rounded. Eyes ovoid and convex, each composed of about 25 facets. Antennae short, reaching hind margin of pronotum, 1st segment thick and subcylindrical, 2nd arcuately extended internally, limbate on its internal margin, 3rd to 8th moniliform, 9th to 10th thick and each transverse, 11th large and ovoid. Maxillary palpi slightly shorter than antennae, 1st segment short, 2nd elongate, gradually thickened distally, gently granulate, 3rd short and ovoid, gently granulate, 4 th largest, about 2.5 times as long as wide, widest at basal $1 / 3$, with a short palpal spine at apex.

Pronotum slightly wider than long, widest at anterior $1 / 3$, weakly convex and sparsely covered with coarse punctures on dorsal surface, with a transverse sulcus at basal $1 / 5$ and a pair of lateral foveae at basal $1 / 3$. Elytra about as long as wide, broadened posteriorly and weakly convex, each elytron with 2 basal foveae. Legs slender, hind tibiae each weakly incurvcd in apical $1 / 3$, with a small mucro at apex.

Abdomen very short, rounded posteriorly, 4th to 8th segment each transverse, 9th sternite composed of a small and ovoid median sclerite and a pair of broad lateral sclerites, each lateral scierite narrowed basally, with an elongate extension on lateral side. Male genitalia very large and ovoid; parameres paird, each narrowed and sinuatc distally, with 3 short setae at apex; median lobe bulbous, with a T-shaped sclerite at apex, basal foramen narrow and transverse; cndophallus very large, composed of a pair of apical sclerites and many long and sharp spines along median line.

Female. Length $1.5 \mathrm{~mm}$. Width $0.6 \mathrm{~mm}$. Similar to male, but body smaller, 2nd antenna1 segment ovoid and hind tibiae without mucro at apex.

Distribution. South Korea (Mt. Chilisan) and Japan (Kyushu).

Holotype, male, Simwon vall., Samnae Myeon, Chconla-buk Do, 13. v. 1991, S. Nomura leg.
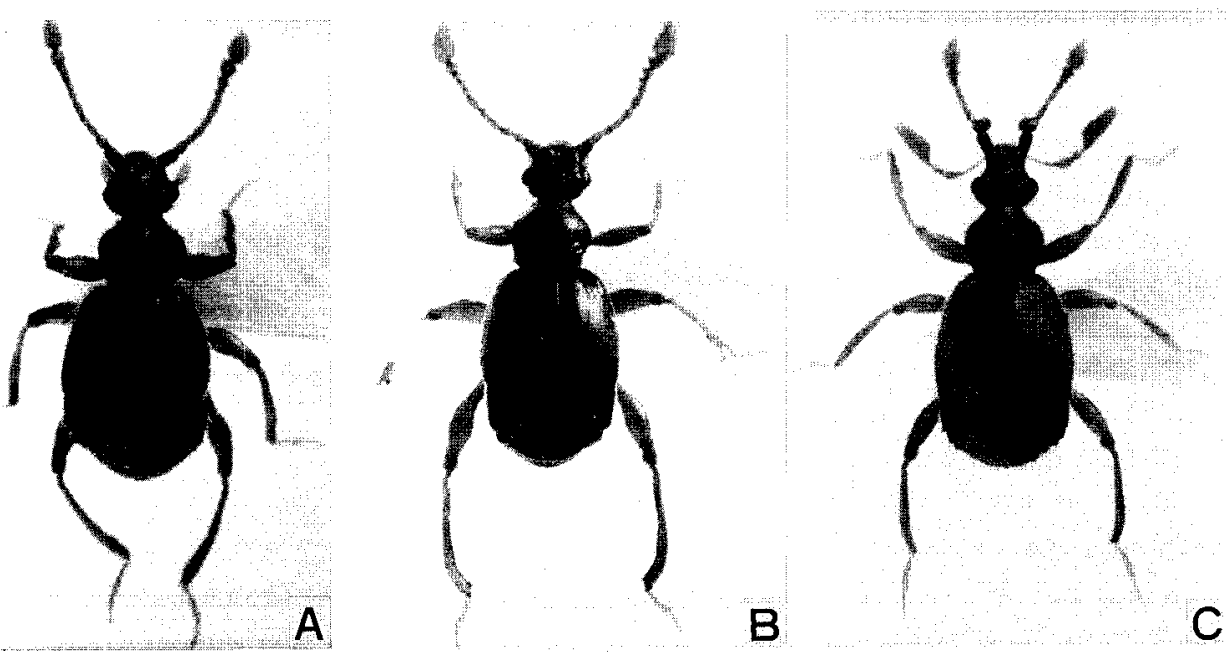

Fig. 9. Dorsal aspects. A: Rybaxis lamellifer Löbl, male; B: Trissemus peninsula _ nus sp. nov., male; C: Bryaxis nogodanensis sp. nov., male. 
Paratypes: 1 male, same data as holotype; 1 female, Jeonglyeong Chi, Samnae Myeon, Cheonla-buk Do, 14. v. 1991, S. Nomura leg.; 1 female, same locality as above, 12. vii. 1991, S. Nomura leg.

Remarks. The new species B. nogodanensis belongs to the subgenus Arcobythus Jeanne1 in having the granulate second to third segments of the maxillary palpus. This species is much related to B. asciicornis Kurbatov, f. inflatipes-ornaticornis recorded from Far East Russia and B. validicornis Löbl in having the arcuately extended second antennal segment, but it differs from them by the median lobe of the aedeagus with a crescent apical sclerite between the parameres.

\section{Bryaxis macheonensis sp. nov.}

Heteromorphous male. Unknown.

(Figs. 10B, I, 11C, D, H, 12A)

\section{Homomorphous male. Length $1.4 \mathrm{~mm}$. Width $0.6 \mathrm{~mm}$.}

Body reddish brown, tarsi light brown, narrowed anteriorly.

Head longer than wide, clypeus short, frons concave on median part, coarsely punctate, vertex gently convex, with a pair of dorsal tentorial pits, covered with dense and coarse punctures, postgenae weakly rounded. Eyes ovoid and convex, each composed of about 25 facets. Antennae short, reaching hind margin of pronotum, 1st segment thick, subcylindrical, 2nd slightly longer than 1st, 1.7 times as long as wide, strongly swollen and subcylindrical, with a cylindrical secretory organ at apical 1/5, 3rd to 8th moniliform, each subglobose, 9th to 10th thick, each transverse, 11th slightly larger than 2nd, ovoid at basal part, subconical at apical part. Maxillary palpi each about as long as antenna, 2nd to 3rd segments gently granulate, 4th segment largest, 2.7 times as long as wide, widest at basal $1 / 3$.

Pronotum slightly wider than long, widest at apical $2 / 5$, rounded at both sides, coarsely punctate on dorsal surface, more sparsely punctate than in vertex. Elytra slightly wider than long, broadened posteriorly, humeri weakly expanded. Legs slender and short, hind tibiae each weakly incurved in apical $1 / 5$, with an acute mucro at apex.

Abdomen short, rounded posteriorly in dorsal view, 4th to 8th segments each transverse, 9th sternite consisting of a small and ovoid median sclerite and a pair of elongate lateral sclerites. Male genitalia small and nearly ovoid; parameres paird, each weakly broadened at middle part, then slightly sinuate and narrowed distally, with 3 small setae at apex; median lobe bulbous, basal foramen small and transverse, with a large and ovoid membranous part on dorsal side, apical projection between parameres; endophallus elongate, composed of a pair of long spines.

Female. Length $1.3-1.4 \mathrm{~mm}$. Width $0.6 \mathrm{~mm}$. Very similar to male, but body slightly smaller, 2nd antenna1 segment narrower and hind tibiae without mucro at apex.

Distribution. South Korea (Mt. Chilisan).

Holotype, male, Samjeong Ri, 14. vii. 1991, S. Nomura leg. Paratypes, 1 male 3 females, same data as holotype.

Remarks. This species B. macheonensis resembles B. kimjongkuki and B. chilimontanus, but different from the former species in the elongate second antennal segment without subcrect hair and the uniformly pubescent pronotum, and from the latter in the secretory organ located at the apical part of the second antennal segment. 


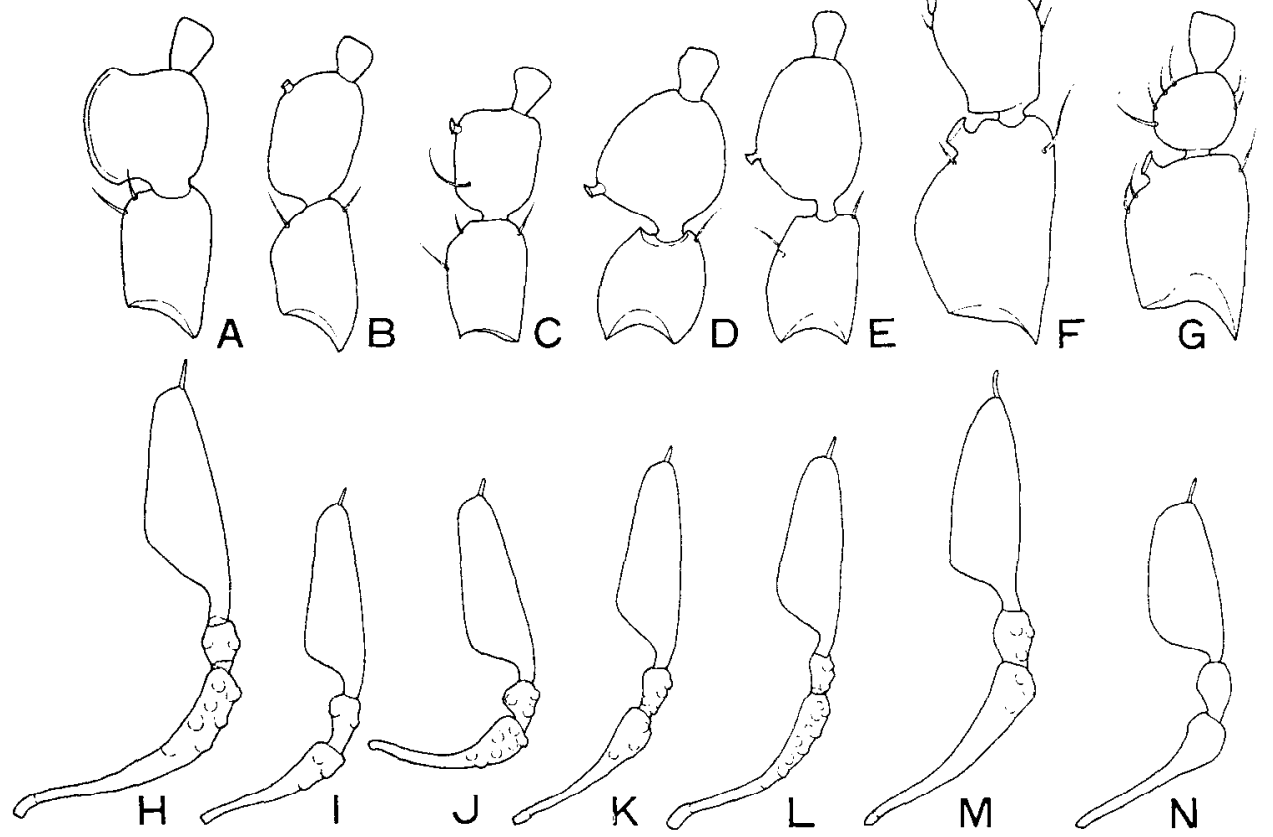

Fig. 10. A-G: 1st to 2nd antennal segments; H-N: maxillary palpi. A, H: Bryaxis nogodanensis sp. nov.; B, I: B. macheonensis sp. nov.; C, J: B. kimjongkuki sp. nov.; D, K: $B$. ieechanyoungi sp. nov.; E, L: B. chilimontanus sp. nov.; F, M: $B$. peninsulanus sp. nov.; $G, N$ : B. coreanus Nomura \& Lee.

\section{Bryaxis kimjongkuki sp. nov.}

(Figs. 10C, J, 11E, F, I, 12B)

\section{Heteromorphous male. Unknown.}

Honioniorphous male. Length $1.4 \mathrm{~mm}$. Width $0.6 \mathrm{~mm}$.

Body reddish brown, maxillary palpi and legs light brown.

Head slightly longer than widle, weakly narrowed anteriorly, clypcus short, arcuate on anterior margin, frons short, concave on median part, vertex gently convex, coarsely punctate, with a pair of dorsal tentorial pits, postgenae short, slightly narrowed. Eyes ovoid and convex, each composed of about 20 facets. Antennae short, reaching hind margin of pronotum, 1st segment thick and long, subcylindrical and gently swollen on inner side, 2ndabout as wide as 1st, shorter than 1st, subcylindrical, 1.3 times as long as wide, slightly flattened on inner side, with a small secretory organ at apical $1 / 4$ and a long and suberect seta at basal $1 / 3$ on dorsal side, 3rd to 8th moniliform, each small and sugblobose, 9th to 10th thick, each transverse, 11th largest and subconical at apical part. Maxillary palpi long, each slightly shorter than antenna, 2nd to 3rd segments slender, clearly granulate, 

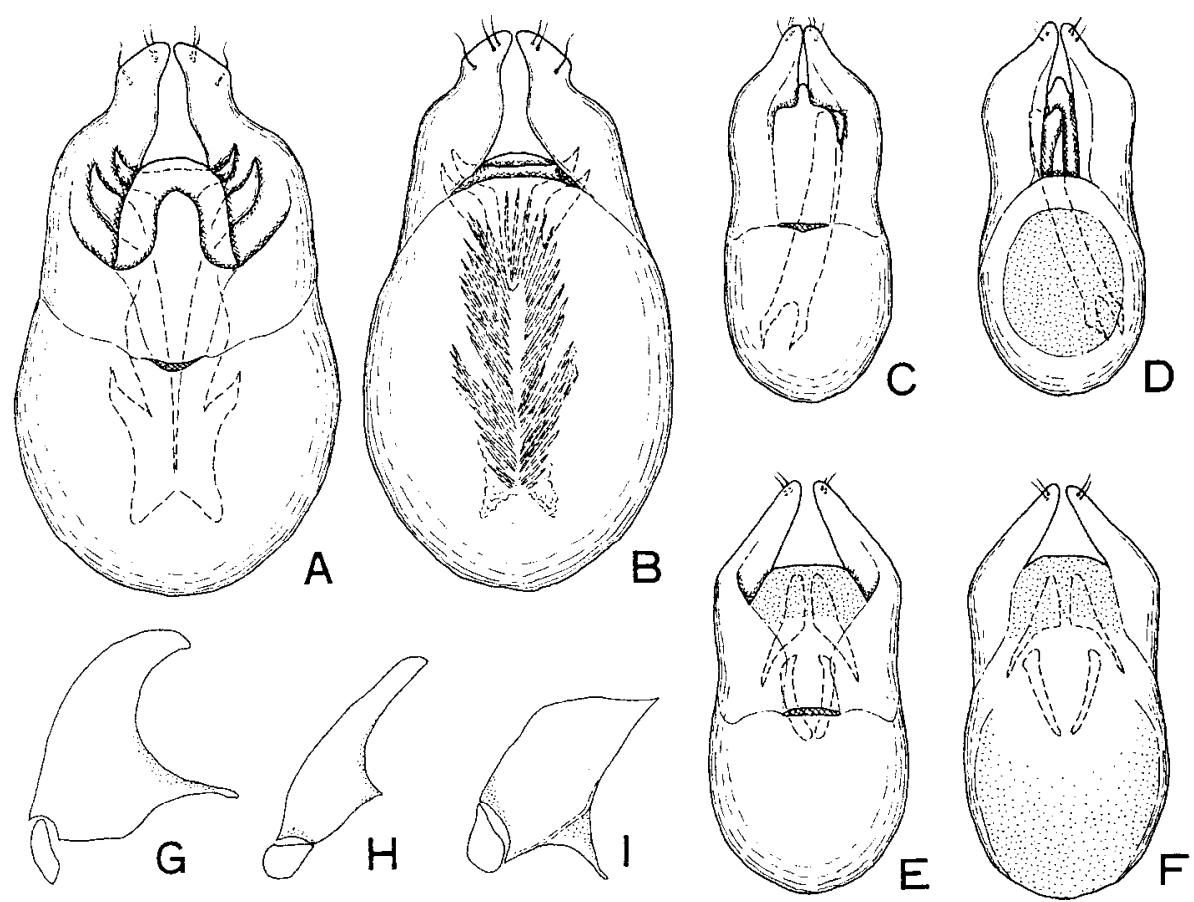

Fig. 11. A, C, E: male genitalia in ventral view; B, D, F: ditto, in dorsal view; GI: 9th sternite, median and right lateral sclerites. A-B, G: Bryaxis nogodanensis sp. nov.; C-D, H: B. macheotzensis sp. nov.; E-F, I: B. kimjongkuki sp. nov.

4th largest, about as long as 2nd t 3rd, 2.7 times as long as wide, widest at basal 1/4, outer margin gently arcuate.

Pronotum wider than long, roundly expanded on both sides, widest at anterior 3/7, with a transverse sulcus and a pair of lateral foveae at posterior $1 / 4$, dorsal surface densely covered with coarse punctures, short pubescence and some suberect long hairs. Elytra about as long as wide, gently narrowed anteriorly, humeri weakly expanded. Legs short and slender, hind tibiae each slightly incurved in apical $1 / 3$, with a small mucro at apex.

Abdomen very short, rounded posteriorly, 4th to 8th segments each short and transverse, 9th sternite composed of a small and ovoid median sclerite and a pair of broad lateral sclerite, each lateral sclerite nearly quadrangular, with a narrow lateral strut. Male genitalia small and weakly sclerotized; parameres paird, each narrowed distally, bent internally near the middle, then straight toward apex, with 2 small setae at apex; median lobe bulbous, membranous on dorsal side, with a narrow and transverse basal foramen; endophallus composed of 2 pairs of elongate spines.

Female. Length 1.3-1.4 mm. Width 0.6 mm. Very similar to male, but 2nd antenna1 segment narrower and ovoid, without secretory organ nor long setac, hind tibiae without mucro at apex.

Distribution. South Korea (Kyonggi Do, Kangweon Do).

Holotype, male, Kwangnung, Pochon Gun, Kyonggi Do, 14-19. v. 1992, S. Nomura leg. 
Paratypes, 4 females, same data as holotype; 2 females, same locality as above, 16. vii. 1992, S. Nomura leg.; 4 males 5 females, Bougmyong Ri, Chunchon Gun, Kangweon Do, 22-23. v. 1992, S. Nomura leg.

Remarks. The new species $B$. kimjongkuki is very similar to B. macheonensis sp. nov., but antennae having short and weakly flattened second segment with a suberect seta on the dorsal side and the pronotum covered with suberect long hairs.

Etymology. This species name is dedicated to Dr. Jong Kuk Kim for his kind assistance to our study and this project.

\section{Bryaxis leechanyoungi sp. nov.}

(Figs. 10D, K, 12C, 13A, B, G)

Heteromorphous male. Unknown.

Homomorphous male. Length $1.4 \mathrm{~mm}$. Width $0.6 \mathrm{~mm}$.

Body reddish brown, thick and narrowed anteriorly, 2nd to 11th antenna1 segments, maxillary palpi and legs yellowish brown.

Head longer than wide, weakly narrowed anteriorly, clypeus short, nearly horizontal on anterior margin, frons short, longitudinally carinate on anterior part, gently depressed on middle part, vertex slightly convex, coarsely punctate, with a pair of dorsal tentorial pits, postgenae short and slightly rounded. Eyes ovoid and convex, each composed of about 20-25 facets. Antennae short, reaching hind margin of pronotum, 1st segment thick and ovoid, 2nd longer than 1st, strongly swollen on inner side, thickest and subglobose, with a small and subcylindrical secretory organ at basal $1 / 3$ on inner side, 3rd to 8 th moniliform, each subglobose, 9th to 10th thick, each transverse, 11th slightly longer and narrower than 2nd, subconical at apical part, ovoid at basal part. Maxillary palpi each slightly shorter than antenna, 2nd to 3rd slender, clearly granulate, 4th largest, about as long as 2nd + 3rd, 2.8 times as long as wide, widest at basal 1/3, outer margin almost straight.

Pronotum wider than long, round-sided, widest near the middle, dorsal surface with minute and sparse punctures. Elytra slightly wider than long, clearly convex, weakly narrowed anteriorly, humeri expanded. Legs short and slender, hind tibiae each weakly incurved in apical 1/4, with an acute mucro at apex.

Abdomen short, rounded posteriorly, 4th to 8th segments each transverse, 9th sternite consisting of a small and ovoid median sclerite and a pair of broad lateral sclerite. Male genitalia small and weakly constricted near the middle; parameres paird, each incurved and narrowed at apical part, with a small seta at apex; median lobe bulbous, with an apical projection and an ovoid membranous part on dorsal side; endophallus composed of a pair of long spines.

Female. Length 1.3-1.5 mm. Width $0.6 \mathrm{~mm}$. Very similar to male, but antennae with narrower and ovoid 2nd segment without secretory organ, hind tibiae without mucro at apex.

Distribution. South Korea (Kyonggi Do, Kangweon Do).

Holotype, male, Kwangnung, Pochon Gun, Kyonggi Do, 14-19. v. 1992, S. Nomura leg. Paratypes, 1 male 2 females, Gamjong Ri, Chunchon Gun, Kanweon Do, 23. vii. 1992, S. Nomura leg.; 1 male 5 females, Bougmyong Ri, Chunchon Gun, Kangweon Do, 22-23, v. 1992, S. Nomura leg.; 1 male, same locality as above, 21. vii. 1992, S. Nomura leg. 

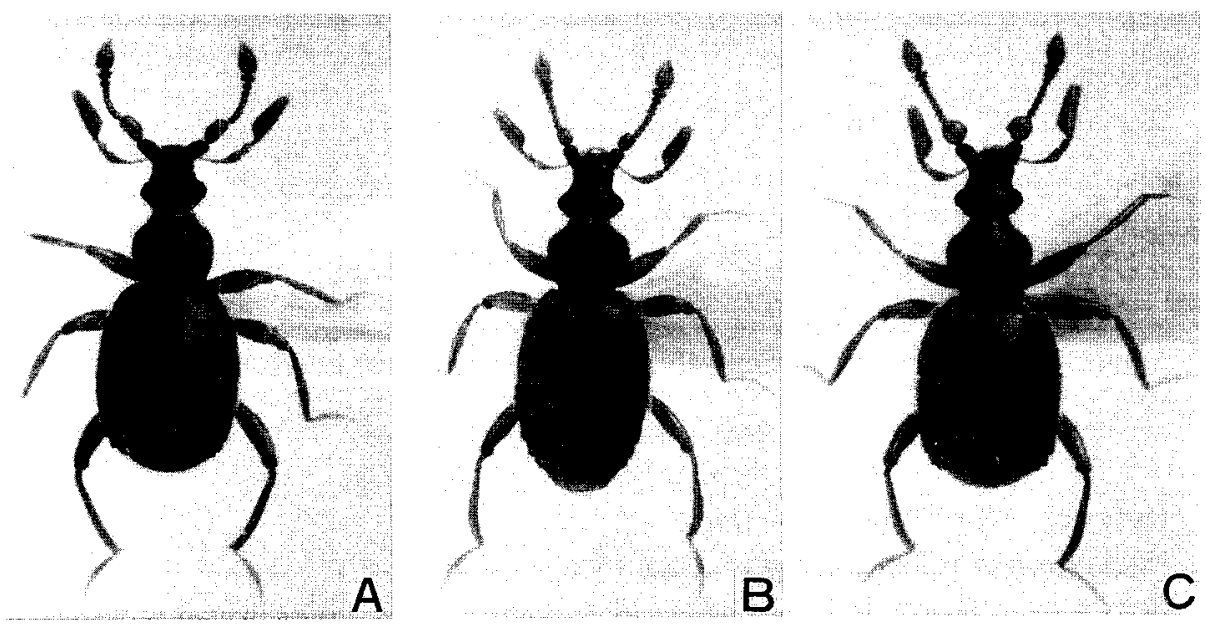

Fig. 12. Dorsal aspects. A: B. macheonensis sp. nov.; B: B. kimjongkuki sp. nov.;

$C$ : B. leechanyoungi sp. nov.

Remarks. This species B. leechanyoungi is similar to B.hallamontanus Nomura \& Lee in having the subglobose and internally projected second antennal segment. But second to third segments of the maxillary palpi granulate and the pronotum sparsely covered with minute punctures.

Etymology. The species name is dedicated to Prof. Chan Young Lee of Kangweon Univ. for his kind assistance to our study in various ways.

\section{Bryaxis chilimontanus sp. nov.}

(Figs. 10E, L, 13C, D, 14A)

Heteromorphous male. Unknown.

Homomorphous male. Length $1.4 \mathrm{~mm}$. Width $0.6 \mathrm{~mm}$.

Body reddish brown, narrowed anteriorly, tarsi light brown.

Head longer than wide, weakly narrowed anteriorly, clypeus short, arcuatc on anterior margin, frons gently carinate at anterior part, shallowly depressed on dorsal surface, vertex slightly convex, with a pair of dorsal tentorial pits and coarse punctures. Postgenae short, gently rounded. Eyes small and ovoid, composed of about 25 facets each. Antennae short, reaching basal margin of elytra, 1st segment thick and ovoid, 2nd about as long as 1st, wider than $1 \mathrm{st}, 1.5$ times as long as wide, swollen and ovoid, with a subcylindrical secretory organ at basal $1 / 5$ on inner side, 3rd to 8th moniliform, each subglobosc, 9th to 10th thick, each transverse, 11th largest and ovoid. Maxillary palpi each slightly shorter than antenna, 2nd to 3rd segments slender, gently granulate, 4th largest, slightly longer than 2 nd $\mathrm{t} 3 \mathrm{rd}$, about 3 times as long as wide, widest at basal $1 / 3$, then weakly narrowed distally.

Pronotum wider than long, round-sided, widest at anterior 2/5, sparsely covered with coarse punctures and pubescence on dorsal surface. Elytra as long as wide, weakly narrowed anteriorly, 

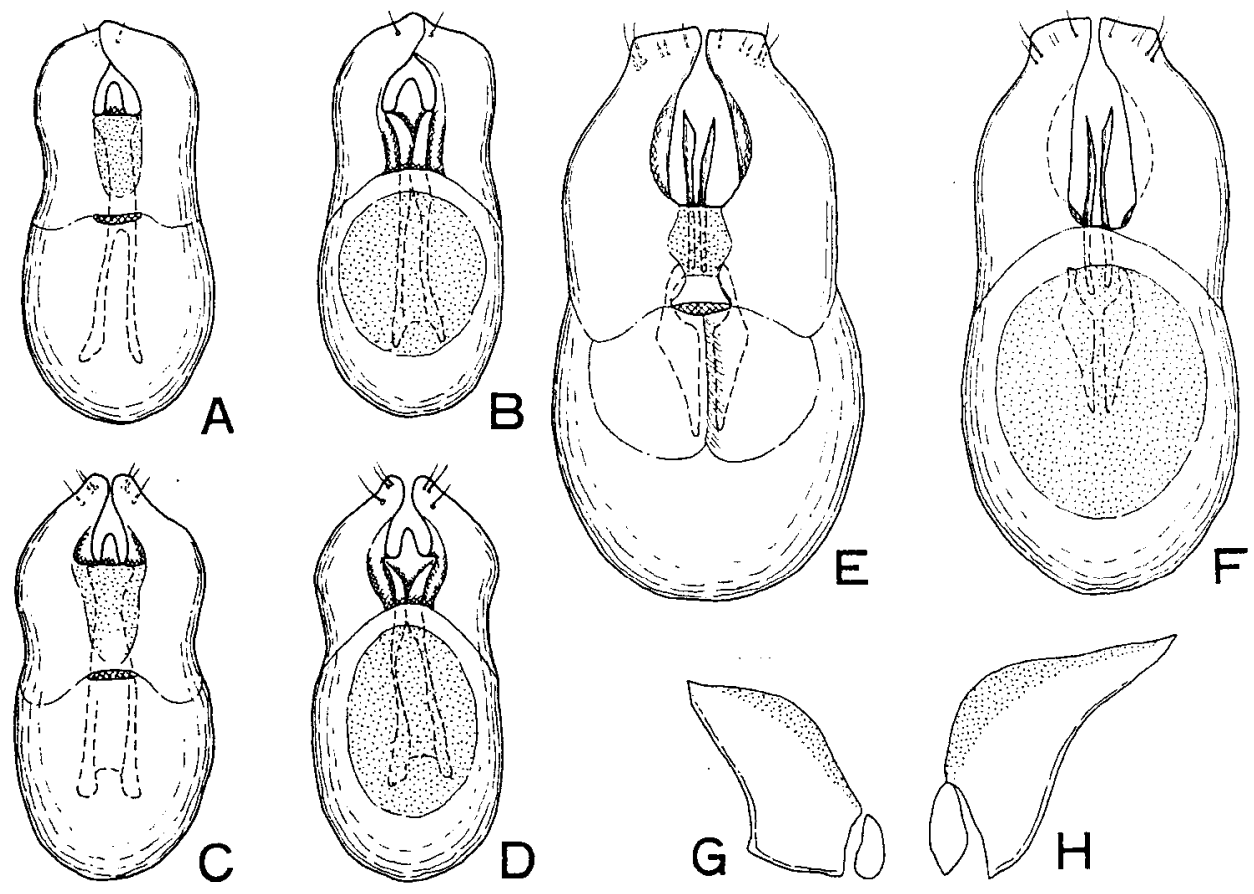

Fig. 13. A, C, E: male genitalia in ventral view; B, D, F: ditto, in dorsal view; G$\mathrm{H}, 9$ th sternites, median and lateral sclerites. A-B, G: B.leechanyoungi sp. nov.;

C-D: B.chilimontanus sp. nov.; E-F, H: B. peninsulanus sp. nov.

convex, humeri gently expanded. Legs short and slender, fore tibiae slender, each slightly emarginate at apical $1 / 3$ on inner side, hind tibiae each gently incurved in apical $1 / 3$, with an acute mucro at apex.

Abdomen very short and transverse, rounded posteriorly. Male genitalia small and gently constricted near the middle; parameres paired, each weakly sinuate and slightly narrowed distally, with 3 small setae at apex; median lobe bulbous, with an apical projection between parameres and an ovoid membranous part on dorsal side; endophallus composed of a pair of long spines.

Female. Length $1.4 \mathrm{~mm}$. Width $0.6 \mathrm{~mm}$. Similar to male, but 2nd antenna1 segment narrower and ovoid without secretory organ and hind tibiae without mucro at apex.

Distribution. South Korea (Mt. Chilisan).

Holotype, male, Samjeong Ri, Macheong Myeon, Cheonla-buk Do, 11. v. 1991, S. Nomura leg. Paratype, female, same data as holotype.

Remarks. B. chilimontanus is similar to B. leechanyoungi, but the antennae with the ovoid second segment with a secretory organ at the basal $1 / 5$ and the pronotum covered with coarse punctures. 


\section{Subgenus Btyaxis s. str.}

The nominotypical subgenus is characterized by the antennae with the first segment having a secretory organ and the swollen or projected second segment. This subgenus has been unknown from Asia, then it is recorded from Asia for the first time.

\section{Bryaxis peninsulanus sp. nov.}

(Figs. 10F, M, 13E, F, H, 14B)

Heteromorphous male. Length $1.6-1.7 \mathrm{~mm}$. Width 0.7-0.8 mm.

Body reddish brown, narrowed anteriorly and thick, maxillary palpi and tarsi light brown.

Head longer than wide, narrowed anteriorly, clypeus weakly expanded, arcuate on anterior margin, frons narrowed, longitudinally carinate at apical part, weakly depressed and glabrous at middle part, vertex gently convex, sparsely punctate, with a slight longitudinal carinae and a pair of dorsal tentorial pits, weakly concave around the tentorial pits, postgenae broad and slightly rounded. Antennae short and slender, reaching hind margin of pronotum, 1st segment elongate and thick, roundly expanded on inner side, with a mushroom-like secretory organ at apical part of the inner side, 2nd thick, strongly swollen internally and projected apically, 3rd to 8th moniliform, each subglobose, 9th wider than 8th, subglobose, 10th wider than long, thick, 11th about as long as 1st, ovoid. Maxillary palpi each clearly shorter than antennae, 2nd to 3rd segments slender, weakly granulate, 4th slightly shorter than 2nd t 3rd, 2.8 times as long as wide, widest at basal 1/4, outer margin gently arcuate.

Pronotum slightly wider than long, round-sided, widest near the middle, dorsal surface convex, sparsely covered with minute punctures, with a transvcrsc sulcus at basal $1 / 5$ and a pair of lateral foveae at basal 1/4. Elytra wider than long, weakly convex, narrowed anteriorly, sparsely punctatc and pubescent. Legs long, thick on femora, fore tibiae each deeply emarginate on inner side, in apical 1/3, basal part of the emargination acutely projected anteriorly, hind tibiae slender, each with a long and acute mucro at apex.

Abdomen very short, rounded posteriorly in dorsal view, 4th to 8th segments cach transverse, 9th sternite comprising of a small and ovoid median sclerite and a pair of broad lateral sclcritcs. Male genitalia large and strongly sclerotized; parameres paired, cach slightly incurved, truncate at apex, with 5-6 small setae at apex; median lobe bulbous and strongly projected ventrally, with an ovoid membranous part on dorsal side; endophallus composed of a pair of long spines, each spine very slender at apical part, broadened and curved near the middle.

Homomorphous male. Unknown.

Female. Length 1.5-1.7 mm. Width $0.7 \mathrm{~mm}$. Similar to male, but 1st to 2 nd segments narrow and without secretory organ nor projection, legs slenderer than in heteromorphous male, hind tibiae without mucro at apex.

Distribution. South Korea (Mt. Chilisan).

Holotype, male, Jeonglyong Chi, Samnae Myeon, 14. v. 1991, S. Nomura leg. Paratypcs, 3 males 1 female, same data as holotype; 1 male 1 female, Samjcong Ri, Macheon Myeon, Cheonla- 
buk Do, 11. v. 1991, S. Nomura leg.; 2 males 2 females, same locality as above, 14. vii. 1991, S. Nomura leg.

Remarks. B. peninsulanus is most closely allied to the type-species of the genus, B.bulbifer (Reichenbach) in habing the swollen first antenna1 segment with a mushroom-like secretory organ and the anteriorly projected second segment. This Korean species is distinct in the nominotypical subgenus by the granulate maxillary palpi.

\section{Subgenus Bythobletus Reitter}

Bythobletus Reitter, 1909, Faun. germ., Käf., 2: 214; Raffray, 1911, Psel., Coleopt. Cat., (27): 115 (=Bryaxis); Jeannel, 1950, Col. Psel., Faun. Fr., 53: 232 (as a subgen. of Arcopagus); Jeannel, 1958, Mém. Mus. nat. Hist., Paris (A), 18(1): 85 (as a subgen. of Bryaxis); Newton \& Chandler, 1989, Field. Zool., N. S., (53): 47. Type species: Arcopagus puncticollis Denny, designated by Jeanne], 1950.

Bythoblethus; Nomura \& Lee, 1992, Esakia, Fukuoka, (32): 70 (misspelling).

This subgenus is distinguished from the others by the swollen first segment with a secretory organ and the small and subglobose second segment of antennae. It is widely distributed in Palearctic region, and also known from Chcjudo and Japan.

\section{Bryaxis coreanus Nomura \& Lee}

(Fig. 5A, B)
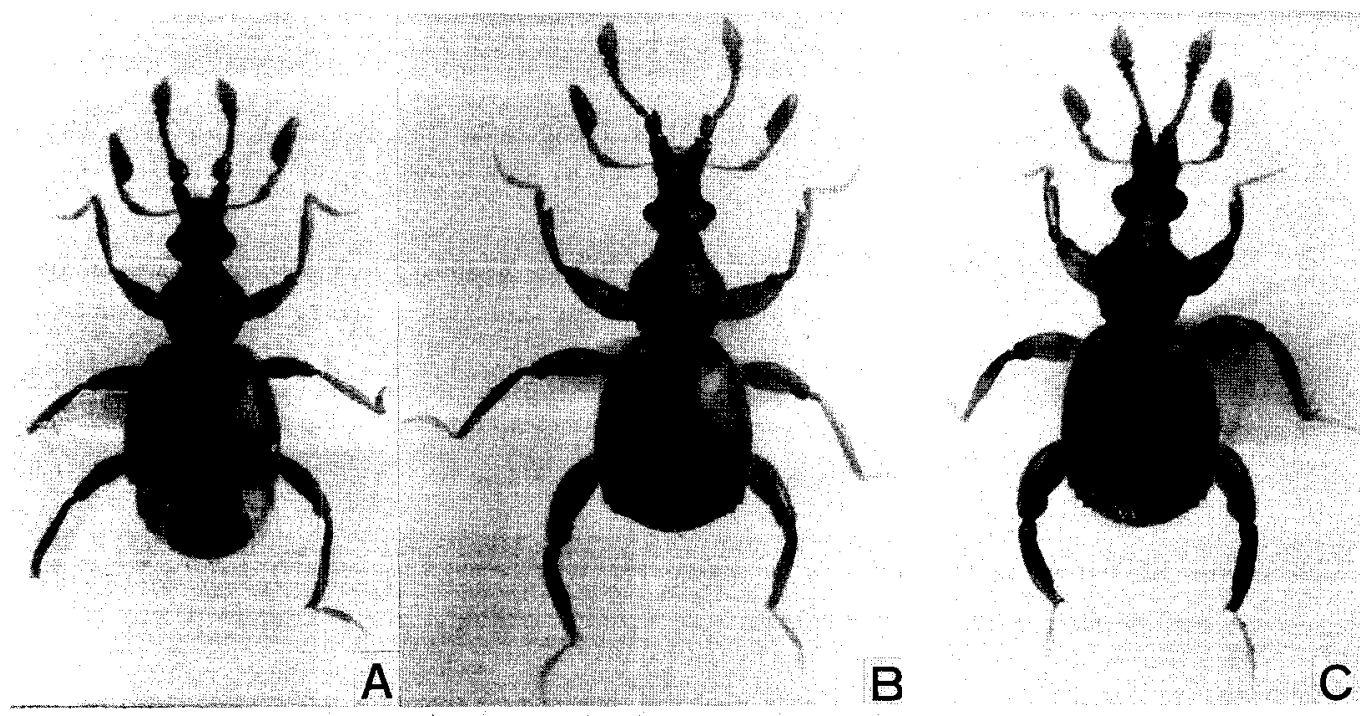

Fig. 14. Dorsal aspects. A: Bryaxis chilimontanus sp. nov.; B: B. peninsulanus sp. noy.; C: B. coreanus Nomura \& Lee. 
Bryaxis coreanus Nomura \& Lee, 1992, Esakia, Fukuoka, (32): 70.

Distribution. South Korea (including Chejudo Is.).

Specimens examined: 1 male 4 females, Kwangnung, Pochon Gun, Kyonggi Do, 14-19. v. 1992, S. Nomura leg.; 5 males, 2 females, Pupan Myon, Hongcheon Gun, Kanweon Do, 20. v. 1992, S. Nomura leg.; 22 males 4 females, same locality as above, 22. vii. 1992, S. Nomura leg.; 2 males 1 female, Bougmyong Ri, Chunchon Gun, Kangweon Do, 22-23. v. 1992, S. Nomura leg.; 1 male 2 females, Samjeong Ri, Macheon Myeon, Cheonla-buk Do, 9. v. 1991, S. Nomura leg.; 1 male, same locality as above, 14. vii. 1991, S. Nomura leg.; 1male, Simwon vall., Samnae Myeon, Cheonla-buk Do, 13. v. 1991, S. Nomura leg.

Remarks. B. coreanus belonging to the subgenus Bythobletus is similar to B. affinis Sharp in the coarsely punctate pronotum and strongly swollen first antennal segment, but the body is larger and the second segment of the antennae having an apically broadened secretory organ.

\section{Tribe Tychini Raffray}

Genus Tychus Leach

Tychus Leach, 1817, Zool. Misc., 3: 84; Aubé, 1833. Type species: Pselaphusniger Reichenbach, by monotypy. (see Nomura \& Lee, 1992 for synonymy.)

\section{Tychus dichotomus Nomura \& Lee}

Tychus dichotomus Nomura \& Lee, 1992, Esakia, Fukuoka, (32): 72.

Distribution. South Korea (including Chejudo Is.).

Specimens examined: 1 female, Pupan Myon, Hongcheon Gun, Kanweon Do, 20. v. 1992, S. Nomura leg.; 1 female, Bougmyong Ri, Chunchon Gun, Kangweon Do, 21. vii. 1992, S. Nomura leg.

Remarks. This species was described from Chejudo Island, Korea and characterized by the aedeagus having a bifurcate dorsal apophysis on the median lobe, the very thick antenna and the broader body.

\section{Genus Tainochus Kurbatov}

Tainochus Kurbatov, 1992, Zool. Zh., Moskow, 71(2): 32. Type species: Tainochus imperator Kurbatov, by original designation.

This genus was recently described based on the type-species, T.imperator Kurbatov from Kunashir Is., Southern Kuril Isls. This genus is defined by the trifovcate elytra and the small apophysis on the fourth segment of the maxillary palpi. Two Korean species belong to this genus, namely T. insulicola (Nomura \& Lee), comb. nov. from Chejudo Is. and a new species from Kyong- 
gi Do.

\section{A Key to the Species of the Genus Tainochus Known from South Korea (including Chejudo Is.)}

1. Antennae each long and slender, 4th segment of maxillary palpi strongly narrowed and elongate at basal part; 5th to 6th abdominal sternites flat in lateral part; male genitalia symmetrical insulicola (Nomura \& Lee) (Chejudo Is.)

- Antennae each short and thick, 4th segment of maxillary palpi ovoid; 5th to 6th abdominal sternites each with a pair of deep basilateral concavities; male genitalia asymmetrical

abdominalis sp. nov.

\section{Tainochus abdominalis sp. nov.}

(Fig. 15)

Male. Length $1.5 \mathrm{~mm}$. Width $0.6 \mathrm{~mm}$.

Body reddish brown, maxillary palpi and tarsi light brown, densely covered with long and curved hairs on dorsal surface.

Head longer than wide, clypeus very short and indistinct, frons convex in anterior part, then constricted at anterior $1 / 3$ of the head, vertex convex and sparsely punctate, with a pair of dorsal tentorial pits, postgenae rounded on both sides, with a large hook-like projection on ventral side as in T.insulicola. Eyes well-developed, larger than those of insulicola, ovoid and convex, each composed of about 30 facets. Antennae slightly shorter and wider than those of insulicola, reaching basal margin of elytra, 1st segment longer than wide, subcylindrical, 2nd slightly shorter than 1st, subcylindrical, 3rd slightly longer than wide, thickened distally, 4th to 8 th subequal in width, each subglobose, 9th to 10th very thick, each transverse, 10th larger than 9th, 11th largest, subcylindrical in basal part, subconical in apical part, relative length (width) of each segment from base to apex: 1.9 (1.0): 1.0 (0.9): 0.7 (0.6): 0.5 (0.6): 0.6 (0.6): 0.5 (0.6): 0.5 (0.6): 0.6 (0.6): 1.0 (1.2): 1.1 (1.5): 2.5 (1.8). Maxillary palpi shorter and wider than those of itzsulicola, 1st segment short and tubular, 2nd elongate, strongly thickened in apical $1 / 2$, 3rd short, narrowed in basal part, 4th largest and ovoid, weakly tapered more than in insulicola on basal part, widest at about basal $1 / 5$, with a long palpal spine at apex, and a small projection at inside of the spine as Cylindrarctus, palpal spine 1/3 as long as 4th segment, small projection 1/4 as long as palpal spine, elongate and rounded at apex.

Pronotum slightly wider than long, widest near the middle, convex and minutely punctate, with a pair of lateral foveae at posterior $1 / 4$. Elytra transverse, weakly narrowed anteriorly, each elytron with 3 foveae and 2 sulci, outer sulcus running from the middle foveae to posterior 1/3. Legs slender, fore trochanters short, each with a small denticle on ventral side, hind trochanters very short, each with a large projection on posterior side, the projection broadened distally and acutely projected internally.

Abdomen about as long as elytra, rounded posteriorly, 4th tergite transverse, weakly constricted at anterior $1 / 3$, with a pair of large and round basilateral foveae and a transverse basimedian concavity, 4th sternite with a pair of large transverse grooves the grooves separated to each other by a median longitudinal keel, 5th sternite short, with a pair of large basilateral concavities, 6th slightly 

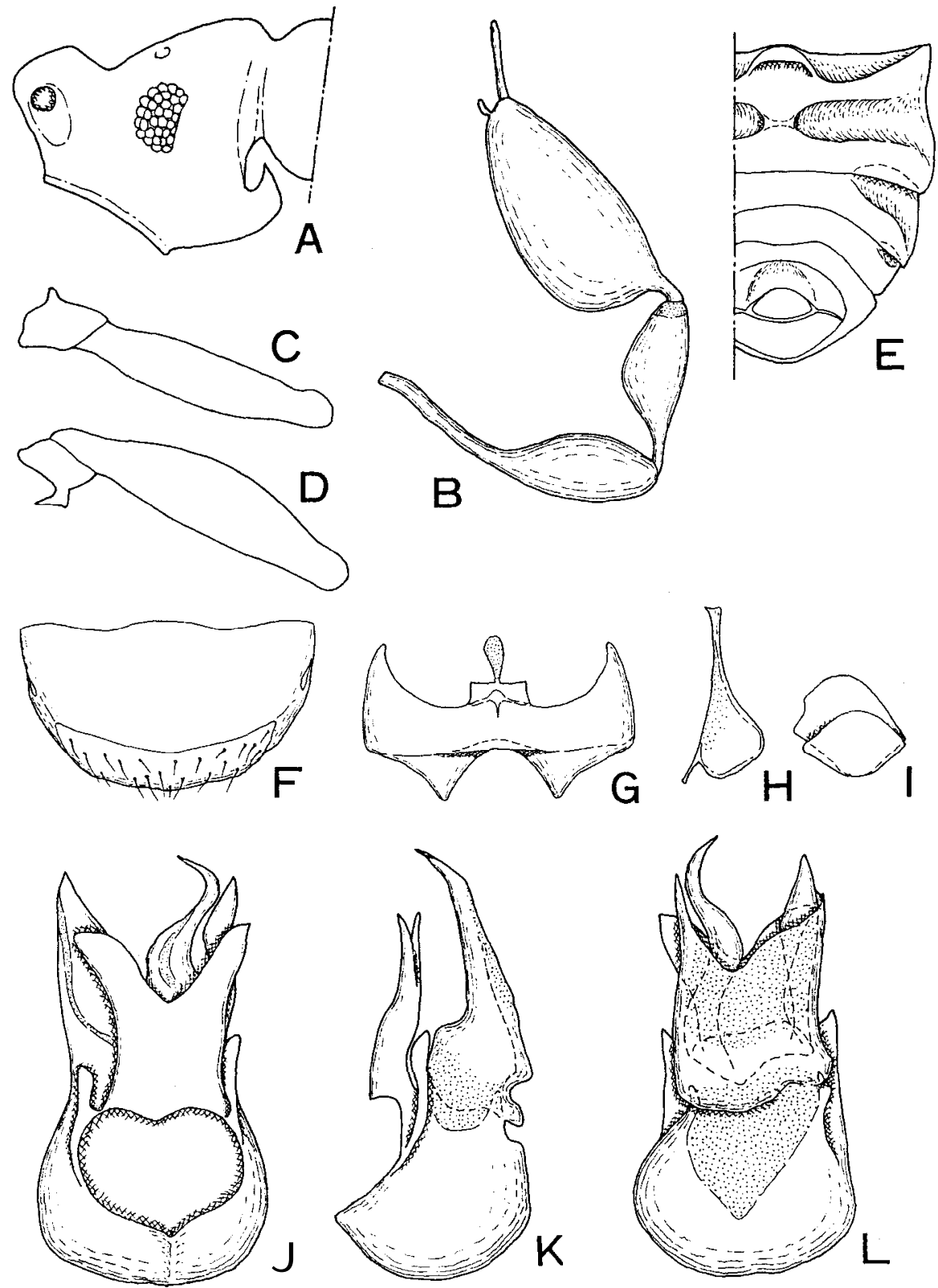

Fig. 15. Tainochus abdominalis sp. nov. A: head lateral view; B: maxillary palpus; C: fore trochanter and tibia; D: hind trochanter and tibia; E: abdomen in ventral view; F: 8th abdominal tergite; G: 8th sternite; H: 9th sternite, right lateral sclerite; I: ditto, median sclerite; J: male genitalia in ventral view; K, ditto, lateral view; L, ditto, dorsal view 
shorter than 5th at lateral parts, with a pair of small basilateral concavities, 8th tergite broad, rounded posteriorly, 8th sternite transverse, arcuately excavated on posterior margin, weakly concave around the excavation, 9th sternite comprising of 3 sclerites, median sclerite transverse, rounded on posterior margin, broadly extended basally, lateral sclerites paird, each tapered in basal part, broadened distally, with an outer projection near apex.

Male genitalia asymmetrical; parameres reduced to very small sclerites attached to both lateral side of basal foramen of median lobe; median lobe large and well sclerotized, basal bulb rounded in basal part, with a large, transverse and cordiform basal foramen, a bifurcate and nearly symmetrical ventral stalk and a large dorsal apophysis; dorsal apophysis with a simply acute left spine and a long and winding right spine in apical part.

Female. Unknown.

Distribution. South Korea (Kyonggi Do).

Holotype, male, Kwangnung, Pochon Gun, Kyonggi Do, 1.5. v. 1992, S. Nomura leg.

Remarks. The new species T. abdominalis is easily separated from T.insulicola described from Chejudo Is. by the shorter and thicker antennae, the ovoid fourth segment of the maxillary palpi and the basilateral concavities at the fifth to sixth abdominal sternites. The male genitalia of this species is also different from those of insulicola (Nomura \& Lee) and imperutor Kurbatov in the asymmetry of the dorsal apophysis. The condition of this aedeagus is suspected to be an intermediate state between the completely symmetrical aedeagi of the other species of this genus or Cylindrarctus in America and the apparently asymmetrical ones of the genus Tychus and its allies.

\section{Subfamily PSELAPHINAE Latreille}

Tribe Pselaphini s. str.

\section{A Key to the Genera of the Tribe Pselaphini from South Korea}

1. Maxillary palpi short, each with ovoid or subcylindrical 4th segment

Curculionellus Westwood

- Maxillary palpi very long, 4th segment very slender at basal part, swollen at apical part; each elytron with 2 basal foveae and a longitudinal carina located between the foveae

Dicentrius Reitter

\section{Genus Curculionellus Westwood}

Curculionellus Westwood, 1870, Trans. ent. Soc. London, 1870, p. 127; Raffray, 1890, Rev. Ent., 9: 138; Raffray, 1900, Proc. Linn. Soc. N. S. Wales, 25: 204; Raffray, 1904, Ann. Soc. ent. Fr., 73: 332; Raffray, 1908, Col. Psel., Gen. Ins.: 311; Raffray, 1911, Psel., Coleopt. Cat., (27): 140; Jeannel, 1951, Rev. fr. Ent., 18(1): 6; Jeannel, 1952, ibid., 19(2): 103; Newton \& 
Chandler, 1989, Field. Zool., N. S., (53): 62. Type species: Curculionellus angulicollis Westwood, designated by Jeannel, 1951.

The genus Curculionellus is known from the tropical area of the Oriental region, New Guinea and Australia, and comprises of twelve species. Present new species is the northernmost record of the genus. This genus is clearly distinguished from the other genera of Pselaphini by the cylindrical fourth segment of the maxillary palpus. It is divided into four groups by Raffray, 1904.

\section{Curculionellus komyungkyuneae sp. nav.}

(Fig. 16)

Male. Unknown.

Female. Length $1.6 \mathrm{~mm}$. Width $0.6 \mathrm{~mm}$.

Body reddish brown, narrowed anteriorly, sparsely covered with blackish, long and curved hairs.

Head strongly constricted in anterior part, clypeus very short and hinded in dorsal view, frons narrowed and strongly convex, weakly broadened in anterior $1 / 4$, with a shallow groove from apex to dorsal tentorial pits, vertex slightly convex, densely punctate and weakly rugose, with a pair of dorsal tentorial pits at basal $1 / 3$ of the head, postgenae shallowly excavated behind the eyes, deeply excavated on ventral side, with dense short hairs. Eyes large, convex and ovoid, each composed of about 20 facets. Antennae slender, reaching basal margin of elytra, 1st segment longest, subcylindrical, 2nd short, slightly longer than wide, subcylindrical, projected internally on its hind margin, 3rd to 8th subequal in width, each subglobose, 9th to 11th successively enlarged apically, 9th to 10th each subglobose, 11th thickest and ovoid, relative length (width) of each segment from base to apex: 2.1 (1.0): 0.9 (0.8): 0.6 (0.7): 0.5 (0.7): 0.6 (0.7): 0.6 (0.7): 0.7 (0.7): 0.7 (0.7): 1.0 (1.0): 1.1 (1.2): 2.0 (1.5). Maxillary palpi short, 1 st segment slender, 2nd thickened distally, 3rd very short, triangular in ventral view, 4th largest, ovoid, 3.5 times as long as wide, with a palpal spine at just outside of the apex.

Pronotum slightly wider than long, widest at the middle, reticulous on dorsal surface, with a pair of lateral foveae at posterior 3/7, and a transverse sulcus at posterior 1/7. Elytra broadened posteriorly, humeri flat, each elytron with 4 foveae, a median sulcus and a broad lateral carina, lateral carina connected with the 2nd inner and 2 nd outer foveae at base, reaching the hind margin of elytra; each elytron with 4 longitudinal striae of the blackish hairs, 1st inner stria along the median line, 2nd inner stria located on the lateral carina, 1st and 2nd outer striae running from humeral angle to lateral part of the hing margin, transverse stria connected with the hind terminals of 2nd inner and 2nd outer striae. Metasternum very broad, shallowly concave at the middle. Legs short and slender, mid trochanters long and thickened distally, each with a small denticle on posterior side near apex, femora rugosely punctate, fore and mid tibiae weakly thickened near the middle, each with 4 to 7 blackish hairs in basal half.

Abdomen larger than elytra, 4th segment largest, with a deep and transverse basal groove and dense short scales around the groove, 5th to 7th successively narrowed and shortened apically, each very short and transverse, 5th to 6th tergites each weakly pointed at median part of the hind margin, 8th tergite nearly triangular in posterior view, 8th sternite crescent, 9th sternite reduced to very small 


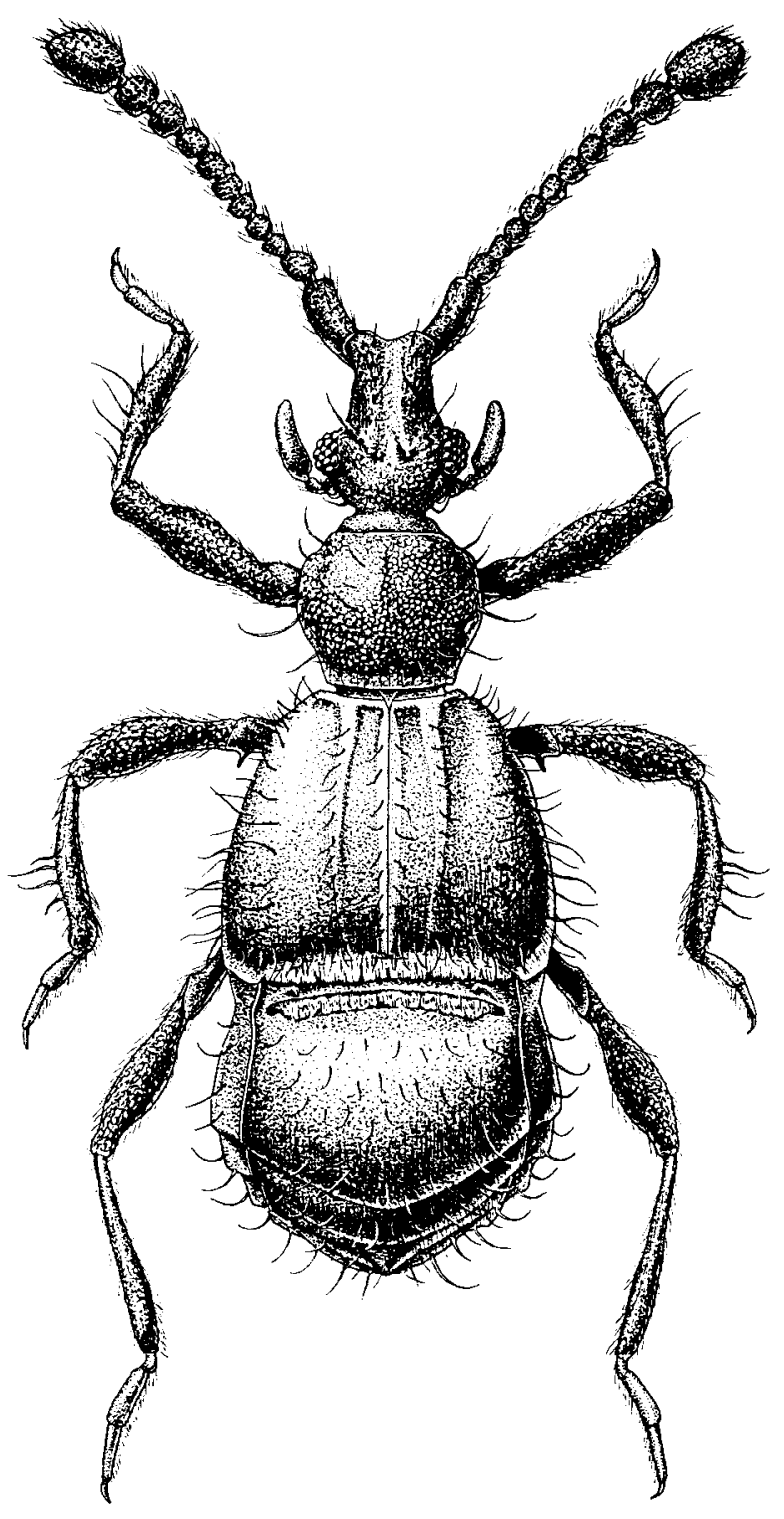

Fig. 16. Dorsal aspect of Curculionellus komyungkyuneae sp. nov.

two sclerites, dorsal sclerite transverse and U-shaped, ventral sclerite narrower than dorsal, $\mathrm{H}-$ shaped.

Distribution. South Korea (Kyonggi Do). 
Holotype, female, Kwangnung, Pochon Gun, Kyonggi Do, 24. ix. 1986, Myongkyun Ko leg.

Remarks. This new species belongs to the group II of Raffray, 1904 by having the bold setae on the dorsal surface of the body and the reticulous pronotum. It is separated from C.hirtus by the indistinct club of antennae and the large dorsal tentorial pits.

Biological notes. The holotype of this species was captured by the pan trap.

Etymology. The species name is dedicated to the collector of the holotype, Mrs. Myong Kyune Ko.

\section{Genus Dicentrius Reitter}

Dicentrius Reitter, 1882b, Verh. naturf. Ver. Brünn, 20: 208. Type species: Pselaphus merklii Reitter, by monotypy. (see Nomura \& Lee, 1992 for synonymy.)

Pselaphogenius Reitter: Kurbatov, 1989, Psel., In Keys Ident. Ins. Russ. Far East, Vol. 3, Col., Part 1: 359 .

\section{Dicentrius cornuncs sp. nov.}

(Figs. 17, 18A, B)

Male. Length $1.7 \mathrm{~mm}$. Width $0.7 \mathrm{~mm}$.

Body reddish brown and shiny, narrowed anteriorly, covered with shallow and reticulous punctures on head, pronotum and legs.

Head elongate, 1.7 times as long as wide, clypeus very short, arcuate on anterior margin, hinded by frons, frons strongly projected anteriorly, weakly constricted near the middle, with a deep median longitudinal sulcus in anterior $1 / 5$ of head, a shallow median depression just behind the constriction, and a pair of shallow depression in front of the dorsal tentorial pits, vertex slightly convex, with a pair of dorsal tentorial pits justinside eyes, postgenae broad, weakly rounded, strongly projected on ventral side. Eyes very small, each composed of 7-8 facets. Antennae slender, reaching basal margin of elytra, 1st segment elongate and subcylindrical, 2nd, slightly narrower than 1st and ovoid, 3 rd to 8th subequal in width, each ovoid and longer than wide, 9th to 10th thicker than 2nd, 11th largest and ovoid, relative length (width) of each segment from base to apex: 2.2 (1.1): 1.2 (1.0): 1.0 (0.7): 0.9 (0.7): 0.9 (0.7): 0.9 (0.7): 1.0 (0.7): 0.9 (0.7): 1.1 (1.0): 1.4 (1.2): 3.0 (1.9). Maxillary palpi very long and slender, 1st segment elongate and tubular, weakly curved laterally near the base, 2nd about 1.5 times as long as 1st, thickened distally in apical 1/3, 3rd very short, triangular in dorsal view, 4th longest, about as long as 1 st $\mathrm{t} 2$ nd, weakly thickened at base, strongly swollen in apical $1 / 3$, with 2 projections at apex, palpal spine on the outer projection.

Pronotum slightly wider than long, rounded at both sides, sparsely covered with short pubescence, with a shallow median depression at posterior $1 / 5$ and a pair of lateral foveae at posterior $1 / 3$. Elytra slightly wider than long, trapezoid, strongly narrowed anteriorly, covered with short scales on median part of hind margin, each elytron with 2 basal depressions, a longitudinal carina and 2 striae of pubescence, inner striae on the carina. Legs short and slender, with dense pubescence.

Abdomen wider than elytra, widest near the middle, rounded posteriorly, 4th segment predomi- 

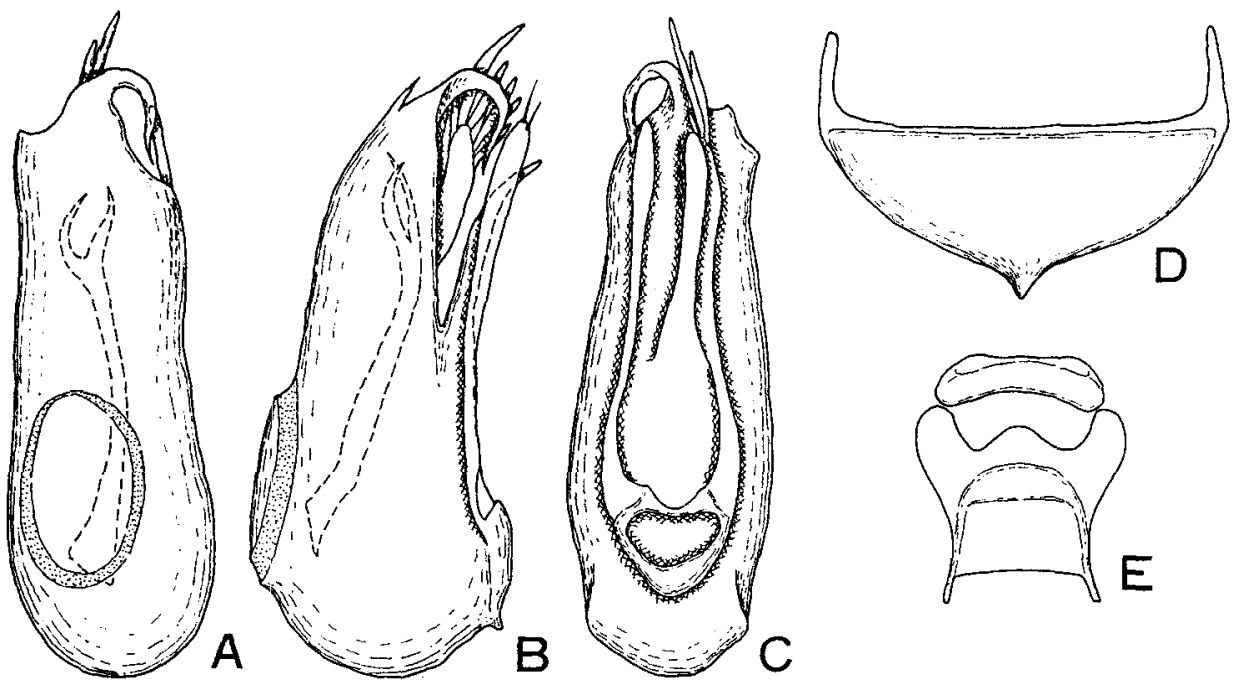

Fig. 17. A-C: Dicentrius cornurus sp. nov., male; D-E: ditto, female. A: male ganitalia in dorsal view; B: ditto, lateral view; C: ditto, ventral view; D: 8th abdominal tergite; E: 9th sternite and genital plate.

nantly large, depressed and covered with short hairs on basimedian part, 5th to 6th very short and transverse, 7th about as long as 5th $\mathrm{t}$ 6th, narrowed posteriorly, 8th tergite nearly trapezoid in posterior view, 8th sternite semicircular. Male genitalia asymmetrical and well-sclerotized; parameres paired, each elongate and strap-like, right paramere with 4-5 bold setac near apex, left longer than right, with 2 short setae at apex; median lobe bulbous at base, with a shoehorn-like ventral process, a hook-like spine at left side of the apex and an ovoid membranous area on dorsal side, basal foramen small and gently projected; endophallus long and slender, forked and curved dorsally at apex.

Female. Length $1.7 \mathrm{~mm}$. Width $0.6 \mathrm{~mm}$. Very similar to male, but Sth abdominal tergite with a subconical projection near apex.

Distribution. South Korea (Mt. Chilisan).

Holotype, male, Samjeong Ri, Macheong Myeon, Cheonla-buk Do, 11 v. 1991, S. Nomura leg. Paratypes, 1 ex., same data as holotype; 9 exs., Jeonglyong Chi, Samnae Myeon, Cheongla-buk Do, 14. v. 1991, S. Nomura leg.

Remarks. The new species $D$. cornurus resembles the other species of Dicentrius known from Japan, but is easily distinguished from the others by the aedeagus having a hook-like spine on the median lobe in male and by the posteriorly projected eighth abdominal tergite in female. This species is more closely allied to $D$. debilis (Sharp) of Nagasaki, Japan by having the asymmetrical aedeagus with bold setae on its left paramere than to D. tubipenis of Tsushima Is. which is characterized by the almost symmetrical aedeagus without bold setae. 

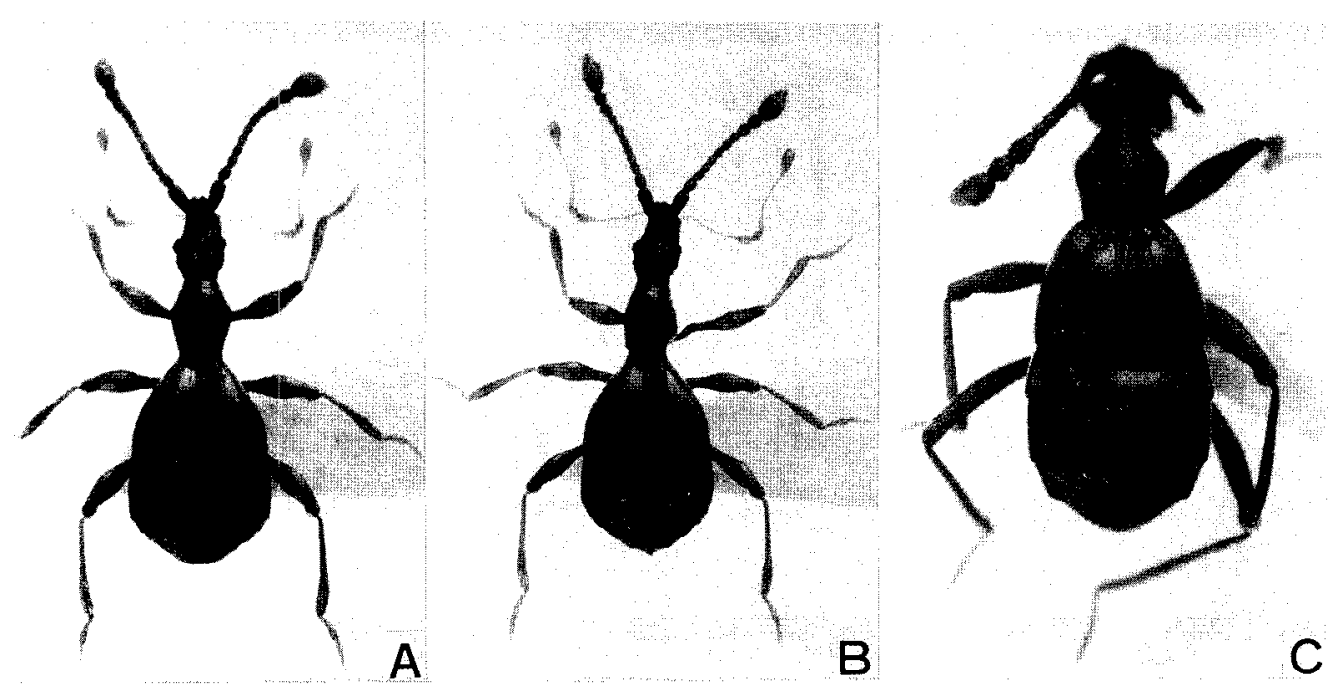

Fig. 18. Dorsal aspects. A: Dicentrius cornurus sp. nov., male; B: ditto, female; C: Tmesiphorus $s p$. indet., female.

\section{Tribe Tnesiphorini Jeannel}

\section{Genus Tmesiphorus LeConte}

Tmesiphorus LeConte, 1849, Boston J. nat. Hist., 6: 75; Brendel, 1890, Bull. Un. Iowa, 1: 230; Raffray, 1890, Rev. Ent., 9: 145; Raffray, 1904, Ann. Soc. ent. Fr., 73: 364; Raffray, 1908, Col.Psel., Gen. Ins.: 373; Jeannel, 1949a, Mém. Mus. nat. Hist., Paris, N. S., 29; 203; Jeanncl, 1959, Ann. Mus. r. Congo belge, Tervuren (Ser. 8, Sci. zool.), 75: 651; Löbl, 1963, Deutsch. ent. 'Zeitschr., N. F., 10 (3/5): 185; Kurbatov, 1989, Psel., In Keys Ident. Ins. Russ. Far East, Vol. 3, Col., Part 1: 361; Newton \& Chandler, 1989, Ficld.Zool., N. S., (53): 57. Type species: Pselaphuscarinatus Say, designated by Lucas, 1920.

Glyptosoma Motschulsky, 1851, Bull. Soc. imp. Nat. Moscou, 24: 480; Besuchct, 1986, Rev. suissc Zool.,93(1): 260 (=Tmesiphorus). Type species: Glyptosoma paulinae Motschulsky, by monotypy.

Sintectes Westwood, 1870, Trans. ent. Soc. London, 1870, p. 129; Raffray, 1890, Rev. Ent., Y: 151

(=Tmesiphorus). Type species: Sintectes carinatus Westwood, by monotypy.

Syntectes Jeanncl, 1949, ibid.: 203 (misspelling). 
(Fig. 18C)

Distribution. South Korea (Kyonggi Do).

Specimens examined: 1 female, Samjeong Ri, 15. v. 1991, K. Morimoto leg.

Remarks. This indeterminate species resembles the Japanese species, T. princeps Sharp in having the fifth abdominal segment with a pair of short longitudinal carinae in the anterior part. It is also similar to T. marani Löbl and $T$. crassicornis Sharp, but cannot be compared with them owing to the lack of the male features.

Biological notes. This myrmecophilous species is captured from the nest of the yellowish ant, Lasius sp. (meridionalis (Bondroit) or umbratus (Nylander)).

\section{Tribe Ctenistini Reitter}

\section{A Key to the Genera of the Tribe Ctenistini from South Korea}

1. Head shorter, postgenae very short, expanded or conically projected on ventral side . . . 2

- Head longer than wide, postgenae broader, flat on ventral side

2. Body larger (about ' $2 \mathrm{~mm}$ ), genae densely covered with scales in front of eyes .... Pilopius Casey

- Body smaller (about $1.5 \mathrm{~mm}$ ), genae with a pair of round tubercles in front of eyes

3. Maxillary palpi penicillate on 3rd to 4th segments

Sognorus Reitter Poroderus Sharp

- Maxillary palpi penicillate on 2nd to 4th segments

(Ctenistes Reichenbach and Poroderopsis Jeannel)

\section{Genus Pilopius Casey}

Pilopius Casey, 1897, Ann. New York Acad. Sci., 9: 617; Raffray, 1908, Col. Psel., Gen. Ins.: 336; Raffray, 1911, Psel., Coleopt. Cat., (27): 146; Jeannel, 1958, Mém. Mus. nat. Hist., Paris (A), 18(1): 112; Kurbatov, 1989, Psel., In Keys Ident. Ins. Russ. Far East, Vol. 3, Col., Part 1:360; Newton \& Chandler, 1989, Field. Zool., N. S., (53): 55. Type species: Pilopius lacustris Casey, designated by Bowman, 1934.

This genus is distinct in this tribe in having the short head and the penicillate second segment of the maxillary palpi. It is distributed in East Asia and Nearctic region.

\section{Pilopius mroczkowskii(Löbl)}

(Fig. 19A)

Ctenistes mroczkowskii Löbl, 1968, Ann. zool., Warszawa, 25(9): 421.

Pilopius mroczkowskii : Mbl, 1973, ibid, 30(9): 330; Kurbatov, 1989, Psel., In Keys Ident. Ins. Russ. Far East, Vol. 3, Col., Part 1: 361.

Distribution. South Korea (including Namhaedo Is.), North Korea. 
Specimens examined: 1 female, lidong Ri, Nomhaedo Is., Kyongsang-nam Do, 19. vii. 1991, S. Nomura leg.; 6 males 3 females, Kwangnung, Pochon Gun, Kyonggi Do, 14-19. v. 1992, S. Nomura leg.; 2 females, Pupan Myon, Hongcheon Gun, Kangweon Do, 22 vii. 1992, S. Nomura leg.

Remarks. This species is very similar to P.discedens known from Japan, but separated by the longer second and seventh antennal segments in male, and the distinctly constricted median lobe of the aedeagus.

\section{Genus Sognorus Reitter}

Sognorus Reitter, 1881, Verh. Kais.-Königl.zool.-bot. Ges. Wien, 31: 458; Raffray, 1890, Rev. Ent., 9: 141; Raffray, 1898, Trans. S. Afr. phil. Sac., 10: 404; Raffray, 1904, Ann. Soc. ent. Fr., 73: 336; Raffray, 1908, Col. Psel., Gen. Ins.: 340; Raffray, 1911, Psel., Coleopt. Cat., (27): 148; Besuchet, 1986, Rev. suisse Zool,93(1): 260; Newton \& Chandler, 1989, Field. Zool., N. S., (53): 56. Type species: Ctenistes calcaratus Baudi, designated by Raffray, 1908.

Agnesia Lokay, 1907, Cas. Ces. Spol. Ent., 4: 87; Besuchet, 1986, 1. c.: 260 (=Sognorus). Type species: Agnesia cilicica Lokay, by monotypy.

Stectenis Raffray, 1908, 1. c.: 339; Besuchet, 1986, 1. c.: 260 (=Sognorus). Type species: Ctenistes simonis Reitter, by monotypy.

Indiella Blattný, 1925, Sbom. Ent. Odd. Narodn. Mus. Praze, 3: 215; Besuchet, 1986, 1. c.: 260 (=Sognorus). Type species: Ctenistes birmanensis Motschulsky, by monotypy.

Sognorites Jeannel, 1949b, Ann. Mus. r. Congo belge, Tervuren (Sér. 8, Sci. zool.), 2: 227; Bcsuchet, 1986, I. c.: 260 (=Sognorus). Type species: Sognorites saegeri Jeannel, by original designation.

Gor70rsu.s Jeannel, 1958, Mdm. Mus. nat. Hist., Paris (A), 18(1): 116; Besuchet, 1986, 1. c.: 260 (= Sognorus ); Kurbatov, 1989, Psel., In Keys Ident. Ins. Russ. Far East, Vol. 3, Col., Part 1: 361. Type species: Ctentstes breviceps Sharp, by original designation.

The genus Sogtzorus is close to Pilopius Casey in having the short head and the penicillate second segment of maxillary palpi, but is separated by the small body and the genae with a pair of tubercles. This genus is widely distributed in the old world, and comprises eleven species.

\section{Sognorus breviceps (Sharp)}

(Fig. 19B)

Ctenistes bt-eviceps Sharp, 1883, Trans. ent. Soc. London, 1883, p. 296.

Ctenisophus breviceps : Kubota, 1943, Trans. Kansai cnt. Soc.,9(1): 8.

Gonorsus breviceps: Jeannel, 1958, Mém. Mus. nat. Hist, Paris (A), 18(1): 116; Löbl, 1977, Bull. Acad. polon. Sci., Ser. Sci. biol., 25(4): 238; Kurbatov, 1989, Psel., In Keys Ident. Ins. Russ. Far East, Vol. 3, Col., Part 1: 361.

Sognorus breviceps :Raffray, 1904, Ann. Soc. ent. Fr., 73: 354; Raffray, 1908, Col. Pscl., Gen. Ins.: 341; Raffray, 1911, Psel., Coleopt. Cat., (27): 148; Besuchet, 1986, Rev. suisse Zool., 93(1): 

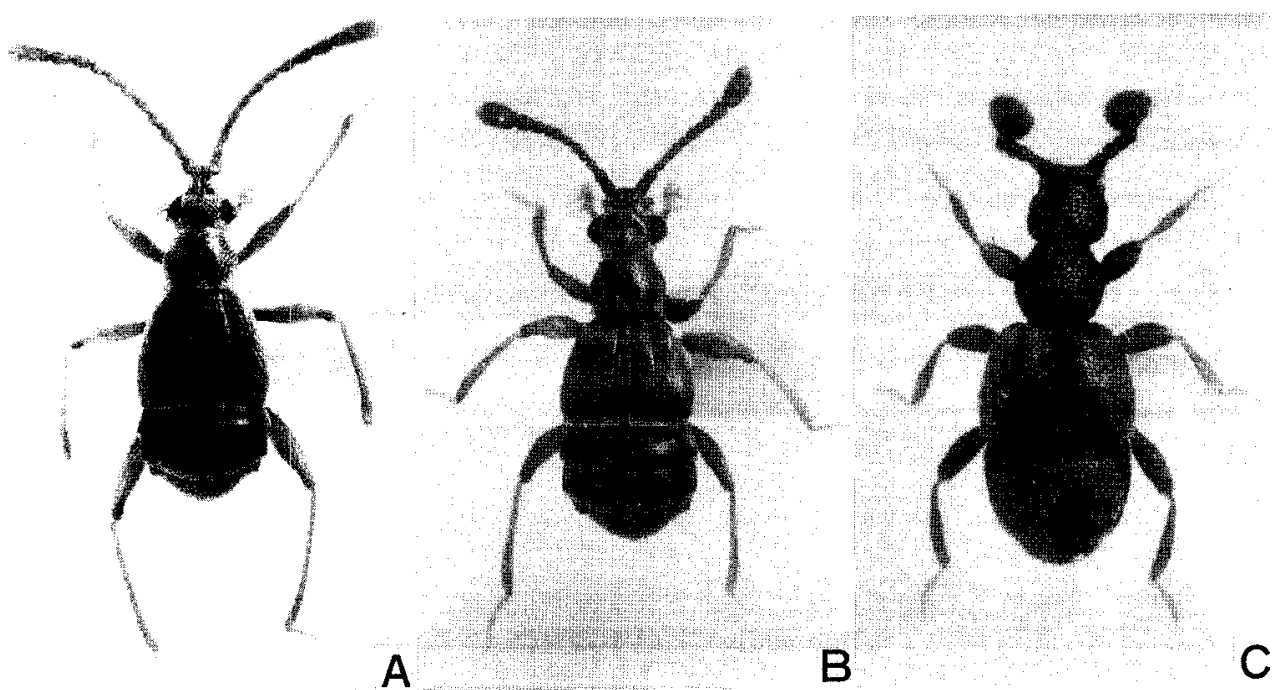

Fig. 19. Dorsall aspects. A: Pilopius mroczkowskii (Löbl), male; B: Sognorus breviceps (Sharp), female; C: Paracyathiger fujiyamai (Kubota), female.

260; Nomura, 1989a, Col. Psel., Ch. L. Jap. Ins., Fukuoka, 1: 292; 1989b, In M. Ejima et al. eds., Nagasaki-ken no Seibutsu, Nagasaki: 186.

Distribution. South Korea, North Korea, Japan (including Tsushima Is.).

Specimens esamined: 1 female, Pupan Myon, Hongchcon Gun, Kangwcon Do, 22. vii. 1992, S. Nomura leg.

Remarks. This species is known from North Korea (Löbl,1977), Tsushima (Nomura, 1989b), Kyushu and Honshu, Japan, and is characterized by the small body, the transverse head with a pair of temporal projections, and the predominantly large antennal club comprising of each elongate eighth to eleventh segments in male.

Tribe Cgathigerini Schaufuss

Genus Paracyathiger Jeanne1

Paracyathiger Jeannel, 1.951: Publ cult. Comp. Diam. Angola, (9): 109; Jeannel,1958, Mém. Mus. nat. Hist., Paris (A), 18(1) 111; Newton \& Chandler, 1989, Field. Zool., N. S., (53): 61; Nomura, 1989c, Jpn. J. Ent., 57(3): 527. Type species: Cyathiger hetcrocerus Raffray, by original designation. 
Cyathiger fujiyamai Kubota, 1943, Trans Kansai ent. Soc., 9(1): 7.

Paracyathiger fujiyamai: Jeannel, 1958, Mém. Mus. nat. Hist., Paris (A), 18(1): 111; Nomura, 1989a, Col. Psel., Ch. L. Jap. Ins., Fukuoka,, 1: 292; 1989c, Jpn. J. Ent., 57(3): 528.

Distribution. South Korea (Kyonggi Do), Japan (Honshu, Shikoku).

Specimens examined. 7 males 5 females, Kwangnung, Pochon Gun, Kyonggi Do, 14-19. v. 1992, S. Nomura leg.; 1 male, same locality as above, 16-19. vii. 1992, S. Nomura leg.

Remarks. This species was described from Honshu, Japan, and is recorded from the continent for the first time. This is a distinct species in the genus by the male antennal club without excavation, and the nearly pentagonal median lobe and the asymmetrical parameres of the male genitalia.

Biological notes. The examined specimens was captured from the rotten wood in the primary forest.

\title{
Subfamily CLAVIGERINAE Leach
}

\author{
Tribe Clavigerini s. str.
}

Genus Diartiger Sharp

Diurtiger Sharp, 1883, Trans. ent Soc. London, 1883, p.329; Kurbatov, 1989, Psel., In Keys Ident. Ins. Russ. Far East. Vol. 3, Col., Part 1: 362. Type species: Diurtiger fossulatus Sharp, designated by Lucas, 1920. (see Nomura \& Lee, 1992 for synonymy.)

\section{Diartiger dentipes Nomura \& Lee}

(Fig. 6C, D)

Diurtiger dentipes Nomura \& Lee, 1992, Esakia, Fukuoka, (32): 77.

Distribution. South Korea (including Chejudo Is.).

Specimens examined: 1 male, Naelyeong Ri, Samnae Myeon, Cheonla-buk Do, 10. v. 1991, K. Morimoto leg.; 28 males 22 females, Samjeong Ri, Macheon Myeon, Chconla-buk Do, 15. v. 1991, S. Nomura leg.

Remarks.. This species was firstly described from Chejudo Is., and is distinguished from the other species of this genus known from Japan by the mid trochanter with a truncate and long spine, the mid femur and tibia each with a small denticle.

Biological notes. This species was collected from the colonies of the ant, Lasius alienus Foerster nesting underside of the stones in Samjeong Ri. But the other one specimen was found on the rotten pine wood by Prof. Morimoto in Naelyeong Ri. 


\section{ACKNOWLEDGEMENT}

We wish to express our hearty thanks to Director general Jae Myeong Jo of Forest Research Institute, Director Seung Kul Park of Chung-bu Forest Experiment Station, and Dr. Jong Kuk Kim of Forest Research Institute, for their kind help on our collecting trip on Kwangnung, Kyonggi Do. We are also much indebted to Proffessor Chan Young Lee, Kangweon National University, for his kind assistance on Kangweon Do. Our cordial thanks are due to Prof. Katsura Morimoto and associate Prof. Osamu Tadauchi of the Entomological Laboratory, Faculty of Agriculture, Kyushu University, and Associate Prof. Michitaka Chûjô of Hikosan Biological Laboratory, Kyushu University for their continuous guidance and valuable advices. I extend special thanks to Dr. K. Ogata of the Institute of the Tropical Agriculture, Kyushu Univ. for his identification of the host ants of the myrmecophilous pselaphids. 
Table 1. Distributions of pselaphid fauna of Korea comparing with Far East, Russia (FE) and species N-Korea S-Korea Chejudo FE Tsushima Japan

Subfam. EUPLECTINAE

Euplectus gibbipalpis Löbl

Leptoplectus vagans Löbl

Philoscotus coreanus sp. nov.

Subfam. BATRISINAE

Batrisus sibiricus Sharp

Batrisodes sp. indet.

B. baejeongdoki sp. nov.

Basitrodes leptothorax Nomura \& Lee

B. myrmecophilus sp. nov.

$B$. sp. 1 indet.

B. sp. 2 indet.

Batriscenellus vicarius Löbl

B. orientalis (Löbl)

$B$. brachygaster sp. nov.

Batrisiella aurita Löbl

\section{Subfam. GONIACERINAE}

Nipponobythus longicornis sp. nov.

Machulkaia dolharubang Nomura \& Lee Triomicruspenicilatus Nomura \& Lee Trissemus crassipes (Sharp)

T. peninsulanus sp. nov.

T.alienus (Sharp)

Rybaxis lamellifer Löbl

Barbiera palparis(Löbl)

Batraxis splendida Nomura

$B$. sp. indet.

Bryaxis mahunkai Löbl

B. ussuriensis Löbl

B. koltzei (Reitter)

B. pa wlowskii Löbl

B. validicornis Löbl

B. nogodanensis sp. nov.

B. macheonensis sp. nov.

$\begin{array}{lll}+ & + & - \\ \mathrm{t} & - & - \\ - & + & - \\ - & - & + \\ - & + & - \\ - & + & - \\ & + & - \\ \mathrm{t} & + & + \\ \mathrm{t} & - & - \\ - & + & - \\ \mathrm{t} & & -\end{array}$

$\begin{array}{lll}+ & - & - \\ & - & - \\ - & - & - \\ - & - & - \\ - & - & - \\ - & - & - \\ + & + & - \\ - & - & + \\ - & - & - \\ - & - & -\end{array}$


Japan.

FE Tsushima Japan

B. kinzjongkuki sp. nov.

B. leechanyoungi sp. nov.

B. chilimontanus sp. nov.

B. hallamontanus Nomura \& Lee

B. peninsulanus sp. nov.

B. coreanus Nomura \& Lee

Tychus dichotomus Nomura \& Lee

Tainochus insulicola (Nomura \& Lee)

T. abdominalis sp. nov.

Subfam. PSELAPHINAE

Curculionellus komyungkyuneae sp. nov. -

Dicerztrius cornurus sp. nov.

D. sp. indet.

Pselaphus striatus Löbl

Tyraphus nitidus Raffray

Tmesiphorus mararzi Löbl

T. sp. indet.

Odontalgus coreanus Löbl

Pilopius mroczkowskii (Löbl)

Poroderus similis (Sharp)

Sognortus breviceps (Sharp)

Centrotoma szeptyckii Löbl

$\begin{array}{cccccc} & + & - & - & - & - \\ - & + & - & - & & - \\ - & + & & - & & - \\ - & & + & & - & - \\ - & + & & - & - & - \\ - & + & + & - & - & - \\ - & + & + & - & - & - \\ - & & + & - & - & -\end{array}$

Paracyathiger fujiyamai ( Kubota) -

Subfam. CLAVIGERINAE

Diartiger dentipes Nomura \& Lee 


\section{References}

Jeannel, R., 1958. Révision des psélaphides du Japon. Mém. Mus. nut. Hist., Paris (A), 18(1):1138.

1959a. Un psélaphide nouveau du Japon. Rev. fr: Ent., 26: 16-18.

1959b. Révision des psélaphides de l'Afrique intertropicale. Ann. Mus. I: Congo belge, Tervuren (Sér: $8^{\circ}$, Sci. zool.), 75: l-742.

Kurbatov, S. A., 1985. New species of pselaphid beetles (Coleoptera) from the Soviet Far East. Rev. Ent. URSS, 64(6): 937-940. (in Russian with English summary)

- 1990. Pselaphidae. In Ler, P. A. ed., Keys to the identification of insects of the Russian Far East., vol. 3, Coleoptera, part. 1: 346-362. (in Russian)

- 1992. New Beetles(Coleoptera, Pselaphidae) from the Primorye and Kunashir Island. Zool. Zh., Moskow, 71(2): 30-35 (in Russian with English summary)

Löbl, I., 1963. Eine neue Art der Gattung Tmesiphorus LeConte.Deutsch. ent. Zeitschr, N.F, 10(3/5): 185-187.

1965. Beitrag zur Kenntnis der Gattung Nipponobythus Jeanne1 (Col., Pselaphidae). Ann. Naturhistor. Mus. Wien, 68: 491-507.

Newton A. F. \& M. K. Thayer, 1992. Current classification and family group names in Staphyliniformia (Coleoptera). Field. Zool., N.S., (67): l-92.

Nomura, S., 1986. Descriptions of two new myrmecophilous species of the family Pselaphidae (Coleoptera) from Japan. Kontyû, Tokyo, 54(3): 498-503.

1988a-c. A revision of the subtribe Acetaliina (Coleoptera, Pselaphidae) from Japan. Part I-III. ibid., 56(2): 251-260; (3): 515-521; (4): 739-751.

1989a. Coleoptera, Pselaphidae. In Y. Hirashima ed., A check list of Japanese insects, 1: 287-293 (in Japanese).

1989b. Pselaphidae from Nagasaki Prefecture. In M. Ejima et al. eds., Nagasaki-ken no Seibutsu, Nagasaki : 185-188 (in Japanese).

1989c. Taxonomic study on the genus Paracyathiger (Coleoptera, Pselaphidae) from Japan. Jpn. J.Ent., 57(3): 527-532.

Nomura, S. \& C. E. Lee, 1992. A revision of the family Pselaphidae (Coleoptera) from Chejudo Island, Korea. Esakia, Fukuoka, (32): 59-80.

(see Nomura \& Lee for the others) 